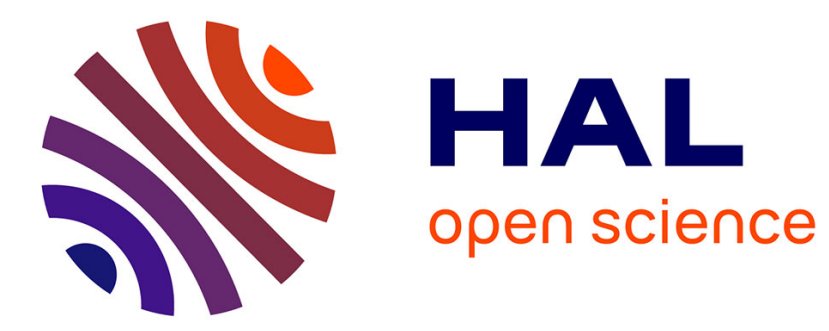

\title{
The Type VI Secretion System in Escherichia coli and Related Species
}

\author{
Laure Journet, E. Cascales
}

\section{To cite this version:}

Laure Journet, E. Cascales. The Type VI Secretion System in Escherichia coli and Related Species. EcoSal Plus, 2016, 7 (1), 10.1128/ecosalplus.ESP-0009-2015 . hal-01778564

\section{HAL Id: hal-01778564 \\ https://hal-amu.archives-ouvertes.fr/hal-01778564}

Submitted on 25 Apr 2018

HAL is a multi-disciplinary open access archive for the deposit and dissemination of scientific research documents, whether they are published or not. The documents may come from teaching and research institutions in France or abroad, or from public or private research centers.
L'archive ouverte pluridisciplinaire HAL, est destinée au dépôt et à la diffusion de documents scientifiques de niveau recherche, publiés ou non, émanant des établissements d'enseignement et de recherche français ou étrangers, des laboratoires publics ou privés. 
1

2

3

4

5

6

7

8

9

10

11

12

13

14

15

16

17

18

19

20

21

22

23

24

25

26

27

28

29

30

31

32

33

34

35

36

37

38

\section{The Type VI secretion system in $E$. coli and related species.}

Running head : Type VI secretion

Correspondence: Eric Cascales: cascales@imm.cnrs.fr

Character count without legend to figures and references (including spaces): 42,000

Table: 1

Figures: 10 


\section{ABSTRACT}

The Type VI secretion system (T6SS) is a multi-protein complex widespread in Proteobacteria and dedicated to the delivery of toxins into both prokaryotic and eukaryotic cells. It thus participates to inter-bacterial competition as well as pathogenesis. The T6SS is a contractile weapon, related to the injection apparatus of contractile tailed bacteriophages. Basically, it assembles an inner tube wrapped by a sheath-like structure and anchored to the cell envelope via a membrane complex. The energy released by the contraction of the sheath propels the inner tube through the membrane channel and towards the target cell. Although the assembly and the mechanism of action are conserved across species, the repertoire of secreted toxins, and the diversity of the regulatory mechanisms and of target cells make the T6SS a highly versatile secretion system. The T6SS is particularly represented in Escherichia coli pathotypes and Salmonella serotypes. In this chapter we summarize the current knowledge regarding the prevalence, the assembly, the regulation and the roles of the T6SS in E. coli, Salmonella and related species.

\section{INTRODUCTION}

The adaptation of bacterial species in their ecological niche relies on specific regulatory circuits to adapt the metabolism and the growth to the extracellular conditions, but also on the release of molecules - siderophores, exopolysaccharides and/or protein toxins - in the milieu. To facilitate their transport through the physical barriers that the membranes represent, protein toxins are specifically selected and secreted by dedicated machineries named "secretion systems". Depending on the nature of the machine itself and on the mechanism of transport of the toxins, these secretory pathways are numbered I-IX. Most of these pathways, including Type I (T1SS), Type II (T2SS), Type III (T3SS), Type IV (T4SS or conjugation), Type V (autotransporters, intimin/invasin and two-partner pathways including contactdependent growth inhibition systems) and curli/fimbriae/chaperone-usher pathways are assembled and active in Escherichia coli and related species such as Salmonella, Shigella, Enterobacter and Citrobacter, and therefore details regarding their architecture, assembly, mechanism of transport as well as the effectors they deliver are described in the corresponding chapters in EcoSalPlus. We will describe here one of the most recently identified secretion pathways, the Type VI secretion system (T6SS).

The T6SS is a multi-protein machine, widespread in Gram-negative Proteobacteria, with an over-representation in $\gamma$-Proteobacteria (1-4). However, T6SS-like machines have been identified and characterized in other phylum such as in Bacteroidetes (5). The assembly of this secretion system requires 13 different subunits, which are usually encoded within a single genetic locus on the chromosome $(2,6)$ (Fig. 1A). Basically, the T6SS can be viewed as a syringe-like structure anchored to the cell membrane by a trans-envelope complex $(3,4,7-9)$ (Fig. 1B). The T6SS syringe is evolutionarily, structurally and functionally related to the puncturing tails of contractile tailed bacteriophages (Fig. 1C), although it is not known whether the genes encoding this structure emerged from co-option of bacteriophage genes $(9$, 10). A large diversity of toxin effectors has been identified in the recent years, from effectors promoting actin modification and disabling eukaryotic cells to peptidoglycan hydrolases targeting competing bacteria. Therefore the T6SS is a versatile weapon targeting cells ranging from bacteria to mammalian hosts. An example of T6SS-mediated inter-bacterial killing between entero-aggregative E. coli (EAEC) and E. coli $\mathrm{K}-12$ is shown in Fig. 2. 


\section{MECHANISM OF ACTION OF THE T6SS}

In the recent years, several aspects of the mechanism of action of the T6SS have been described. Genetic, biochemical and structural characterization of the different T6SS subunits or protein complexes have defined the overall architecture of this secretion apparatus. Timelapse fluorescence microscopy recordings have provided a dynamic view on how the system works. These data, combined with the knowledge on similar contractile structures such as tail bacteriophages or pyocins, allows to design a model for the mechanism of action $(3,4,8,9)$ (Fig. 3). T6SS biogenesis starts with the assembly of the membrane complex (MC) and the tail assembly platform - or baseplate complex (BC) (Fig. 3a). The syringe, composed of the inner tube and capped by the needle spike and wrapped by a contractile structure, the sheath, then polymerizes to form a several hundreds of nm-long tubular structure (Fig. 3b-c). During T6SS assembly, toxin effectors are loaded into the tube or associate with the spike trimer. Contraction of the sheath propels the inner tube/spike, allowing perforation of the target cell membrane and delivery of the effectors (Fig. 3d). The contracted sheath is then disassembled and recycled by a dedicated ATPase named ClpV (Fig. 3e-f).

We will describe in the next sections the genetic organization, the prevalence of T6SS gene clusters, the regulatory mechanisms underlying their expression, as well as the structure, assembly and roles of this secretion machine, emphasizing the current knowledge on the T6SS in E. coli, Salmonella and related species.

\section{GENETIC ORGANIZATION AND PREVALENCE OF T6SS GENE CLUSTERS IN E. COLI, SALMONELLA AND RELATED SPECIES}

Type VI secretion system genes are distributed in Gram-negative Proteobacteria with an over-representation in $\gamma$-proteobacteria (1). Therefore, T6SS genes are found in most E. coli and Salmonella species except the E. coli B and K-12 laboratory strains. The genes encoding components and toxins of the Type VI secretion system are usually clustered and grouped into genetic islands $(1,6)$. The GC content of these regions is generally different from that of the core genome suggesting that they have been acquired by horizontal gene transfer $(1,2,6)$. These gene clusters encode the 13 core components of the T6SS, i.e., all the subunits required to assemble a functional apparatus. Additional genes present in these clusters encode toxins and anti-toxins, adaptor proteins that binds both machine components and toxins, as well as auxilliary proteins required for the assembly of the apparatus or genes of unknown function that might be required for the assembly of the T6SS, the recruitment and proper delivery of the toxin $(3,4,9)$. According to the gene organization and to homologies/similarities, the $E$. coli T6SS gene clusters categorize in three distinct phylogenetic groups: T6SS-1-3 (Fig. 4-5). This observation suggests that these clusters were present in common ancestors or that genetic exchanges occurred between all these strains that may share the same environment. However, the former hypothesis is likely as (i) each of the phylogenetic group is found in both intestinal (AIEC, EAEC, EHEC, EPEC,...) and non-intestinal (UPEC, APEC, MNEC,...) strains and (ii) these groups are not found in bacteria that share similar environments such as Salmonella or Enterobacter species (see below). Among these three phylogenetic groups, the T6SS-1 (Fig. 5A) and T6SS-2 (Fig. 5B) gene clusters are the most commonly found in E. coli chromosomes. For example, the prevalence of T6SS-1, T6SS-2 and T6SS-3 in APEC genomes is $14.6,2.4$ and $0.8 \%$ respectively $(11,12)$. Interestingly, $85 \%$ of the $\mathrm{T}^{2} \mathrm{SS}^{+} \mathrm{APEC}$ strains belong to the virulent phylogenetic groups $(11,12)$. It is worthy to note that, in 
general, the T6SS-2 gene cluster is over-represented in pathogenic strains with high virulence traits. This is particularly clear for entero-aggregative E. coli (EAEC), in which T6SS-2 ${ }^{+}$ strains (e.g., 042) cause diarrhoea whereas T6SS-2 strains (e.g., 17-2, 34b) fail to elicit diarrhoea in human volunteers (13). However, these prevalence information should be taken with care as this does not necessarily mean that T6SSs are directly involved in pathogenesis, but they may prepare the ground for virulence factors by clearing the niche of potential bacterial competitors. Indeed, T6SS-1 and T6SS-2 gene clusters are also found in non pathogenic strains of $E$. coli such as $E$. coli W (14; Fig. 5B); however, in this strain, the T6SS-1 cluster is inactivated by insertion of a mobile element (14) and it is not known whether it is functional.

With the exception of Shigella sonnei and S. enterica Gallinarum, which carry T6SS-2-like gene clusters (Fig. 5B), the T6SS genetic organization in Salmonella, Citrobacter or Enterobacter species is distinct from the E. coli T6SS-1-3 loci. In Salmonella enterica serotypes, T6SSs belong to five phylogenetically distinct families, named as the Salmonella pathogenicity island (SPI) they are encoded on. T6SSs are found in SPI-6 in S. enterica Typhimurium, SPI-19 (similar to T6SS-2) in S. enterica Dublin, Gallinarum or Enteridis, SPI20 and SPI-21 in S. enterica Arizonae and SPI-22 in S. bongori $(15,16)$ (Fig. 4 and 6). However, SPI-6 T6SS remnant genes are found in serotypes Enteridis and Gallinarum suggesting these genes have been lost during evolution. These T6SS loci are characterized by the presence of non-core genes inserted in between the core elements (17). In S. enterica Typhimurium LT2, the organization of the SPI-6 core genes is different from the E. coli species but rather shares synteny with distantly strains such as Burkholderia mallei and Ralstonia eutropha (17). Therefore, Salmonella T6SSs derive from non-E. coli clusters, and have evolved from the original cluster(s) by the acquisition of non-core modules. These modules might have been transferred between strains as a hcp-tae4-tai4 module encoding an Hcp protein and an amidase/immunity pair is found in both S. enterica Typhimurium and Enterobacter cloacae although the core genes differ (18). The addition of these distinct modules during evolution may confer specialized functions to these T6SSs.

168

169

170

171

172

173

174

175

176

177

178

179

180

181

182

183

184

185

186

187

A remarkable difference between the T6SSs in Escherichia and Salmonella strains is the nature of the toxin effectors. T6SS-1-like clusters generally encode effector belonging to phospholipases. T6SS-2 clusters have recombinant hot spots (Rhs) elements bearing putative activities whereas $S$. enterica SPI-6 and Enterobacter cloacae T6SS gene clusters encode amidases and Rhs-linked anti-bacterial activities (Table 1, Fig. 5B and 6).

In addition to the main T6SS gene clusters, additional islands encoding Hcp, VgrG, PAAR and putative toxins could be found disseminated on the genome. As Hcp and VgrG have been shown to be carriers for the transport of the effectors, the existence of $\mathrm{Hcp} / \mathrm{VgrG}$ islands suggests that they correspond to additional modules that adapt to the core machine for the delivery of specific toxins. In several instances, these small islands are inserted within the core gene cluster. As described above, this is particularly visible in the case of the Salmonella enterica sp. Typhimurium SPI-6 gene cluster, in which additional islands are inserted within core genes $(17,19)$ (Fig. 6). It is also very clear when comparing T6SS gene clusters from distinct E. coli species, e.g., a vgrG-tle-tli-paar fragment is found in the T6SS-1-like T6SS operons in EAEC 042, AIEC LF82 and UPEC UT189, but with differences in the vgrG gene and in the effector-immunity pair (Tle effectors of families 1, 3 and 4 respectively) (Fig. 5A and Table 1). 
Most of the strains contain several copies of T6SS gene clusters, this multiplicity likely corresponding to various lifestyles, and thus might be reflected by the regulatory mechanisms and the target cells (20). However, little information are available regarding whether these clusters are differently regulated, have distinct functions or similar functions in different conditions. In EAEC 17-2, two T6SSs are encoded within the phe $U$ pathogenicity island (21). Both T6SSs have anti-bacterial activities (22) but are expressed in different conditions: while the T6SS- 1 cluster is under the control of the Fur repressor and hence induced during iron starvation (23), the T6SS-2 cluster is under the control of AggR, the aggregation master regulator and is expressed in host cells or in synthetic media mimicking the macrophages environment (21). The regulatory mechanisms and function of the E. coli and Salmonella T6SSs are described in more details in the corresponding paragraphs below.

\section{BIOGENESIS AND ARCHITECTURE OF THE T6SS}

The T6SS proteins assemble two modules with different evolution history. As described above, the cytoplasmic syringe-like structure derives from the bacteriophage contractile tail or co-evolved with it from a common ancestor. The assembly of both structures follow a similar sketch: the Hcp tail tube protein polymerizes to form the inner tube, and is tipped by the VgrG membrane-penetrating needle. A sheath-like structure, constituted of the TssBC proteins, polymerizes in an extended, metastable conformation around this inner tube. This two-layered tubular edifice, usually hundreds of nanometers long, is assembled on a platform called the baseplate complex (10). The BC is tethered to the cell envelope via contacts with the second module, the membrane complex $(24,25)$. This $\mathrm{MC}$ is composed of three subunits distributed into the inner and outer membranes. Two of these subunits share sequence homologies with two components of the Type IVb secretion system found in Legionella pneumophila or Coxiella burnetii $(1,6)$.

The best characterized T6SS in E. coli strains and related species is the EAEC T6SS-1 (Sci-1) machinery. The biogenesis of the T6SS starts with the formation of the membrane complex. The MC serves as a conduit for the passage of the Hcp-VgrG needle during contraction. During T6SS biogenesis, it is the first structure to be assembled. Most cells assemble 1 to 3 MCs that remain static (26). Fluorescence microscopy experiments showed that its localization is not spatially restricted to the cell pole or to the septum but rather that it is randomly distributed in the cell envelope (26). The MC is composed of three proteins (Fig. 7A and 7B): the outer membrane TssJ lipoprotein and the inner membrane TssL and TssM proteins (27-29). The EAEC TssJ lipoprotein is tethered to the outer membrane via acyl chains but faces the periplasm (28). Its tri-dimensional structure has been solved (see Fig. 7C; 30). TssJ has a transthyretin fold, i.e., a $\beta$-sandwich of two $\beta$-sheets. Two loops, notably that connecting $\beta$-strands 1 and 2 , mediate contact with the TssM C-terminal domain $(26,30,31)$. TssM is a $130-\mathrm{kDa}$ large protein, composed of three trans-membrane segments in its $\mathrm{N}$ terminal third, whereas the $2 / 3$ of the protein extends through the periplasm, from the inner membrane to the outer membrane-anchored TssJ lipoprotein $(29,30)$. Recently, the crystal structure of the C-terminal portion of the periplasmic region of TssM in complex with TssJ has been solved (Fig. 7C). It is composed of two domains. The structure confirmed that contacts between the two partners are established by interactions of the TssM C-terminal $\beta$ domain with loops L1-2 and L3-4 of TssJ (26). Interestingly, this $\beta$-domain is followed by an $\alpha$-helix (colored purple in Fig. 7C) that inserts into the outer membrane, the insertion being facilitated by the TssJ lipoprotein (26). The 300-amino-acid loop located between TM2 and TM3 shares an NTPase fold, although the presence of Walker A and B motifs is not conserved among TssM homologues. TssM contacts TssL, which is composed of a $\sim 200$ - 
amino-acid cytoplasmic domain anchored to the inner membrane by a unique C-terminal trans-membrane segment, categorizing TssL as a C-tail protein (32). The proper insertion of this $\mathrm{C}$-tail protein requires the $\mathrm{YidC}$ protein and the contribution of the DnaK cytoplasmic general chaperone (32). The structure of the EAEC TssL cytoplasmic domain has been reported (33). It is composed of two bundles of three $\alpha$-helices, with a general shape resembling a fish hook (Fig. 7D; 33). In several instances, the TssL C-terminus is fused to an additional domain of the OmpA/Pal/MotB family that mediates contact with the peptidoglycan (34). In the T6SS-1 of EAEC and other E. coli pathotypes, the TssL protein interacts directly with an additional component, TagL, which carries this motif. In vivo and in vitro studies have shown that this domain anchors the T6SS to the cell wall, and that mutations preventing TagL interaction with the peptidoglycan abolish T6SS function (27). The structure of the EAEC TssJLM complex has been recently solved at 11.6- $\AA$ resolution by negative stain electron microscopy (Fig. 7E; 26). The TssJLM complex has an overall rocketshape structure with 5-fold symmetry. It is composed of 10 copies of each proteins, and its base is composed of the TssL and TssM cytoplasmic and intra-membrane domains. The TssM periplasmic domains form 10 arches starting from the base and converging to the tip of the structure in two layers of 5 pillars. The assembly of the MC starts from the outer membrane and progresses inward: the TssJ lipoprotein recruits TssM and then TssL is added to the TssJM complex (26). The interior of the membrane complex has a size sufficient to accommodate the VgrG protein. The tip complex closes the structure at the outer membrane and it has been proposed that large conformational changes occur - notably a re-organization of the pillars - to allow the passage of the needle upon sheath contraction (26). Indeed, conformational changes in the periplasmic portion of TssM have been reported in Agrobacterium tumefaciens (35).

Once assembled, the $\mathrm{MC}$ serves as a docking station for the $\mathrm{BC}$, i.e. the assembly platform of the T6SS tail (Fig. 8A and 8B). The T6SS BC is constituted of the TssE, -F, -G, $-\mathrm{K}$ and VgrG subunits, which assembles independently of the MC (25). In bacteriophages, the minimal baseplate is composed of six wedges (constituted of the gp6, gp53 and gp25 proteins in bacteriophage T4) that assemble around the spike complex (36). TssE is the T6SS counterpart of the bacteriophage gp 25 wedge protein, and the structure of the EAEC TssE can be modeled based on the structures of gp25 homologues (Fig. 8C; 1, 6, 37). This subunit has been suggested to be connected to the sheath. Although we still lack structural information on TssF and TssG, these proteins share limited homologies with the phage T4 gp6 and gp53 proteins, respectively (25). In agreement with phage baseplate structure, a complex comprising TssE, $\mathrm{F}$, -G and VgrG could be purified from EAEC (25). In addition, it has been shown that TssF, $\mathrm{G}$ and $-\mathrm{K}$ form a stable complex in $S$. marcescens (38). Once assembled, the BC is recruited to the MC via multiple contacts including TssK-TssL, TssK-TssM and TssG-TssM interactions $(24,25)$. The hub of the bacteriophage - and probably of the T6SS - baseplate is the spike complex. The structure of the T6SS spike protein, $\mathrm{VgrG}$, from uropathogenic E. coli CFT073 has been reported (Fig. 8D; 39). This membrane-penetrating needle is a trimer with a base that connects to the inner tube, followed by a region composed of repeats that form a highly stable three-stranded $\beta$-helix, or $\beta$-prism. The structure of the $\beta$-prism of the $E$. coli O157 VgrG protein is also known (Fig. 8D; 40). In most cases, an adaptor protein called PAAR interacts at the tip of VgrG and sharpens its extremity (41). The VgrG proteins sits on the Hcp inner tube. Hcp proteins assemble hexameric rings with an internal lumen of $\sim 40 \AA$ and an external diameter of $\sim 110 \AA$. The structures of several Hcp proteins from diverses bacteria have been reported in the literature, including that of EAEC (Fig. 8E; 42). The Hcp rings stack on each other on a head-to-tail organization, and this assembly is strictly controlled in vivo by additional T6SS subunits $(25,43)$. The assembly of the inner tube is coordinated with that of the sheath but the rigid tube serves as template for sheath 
polymerization (43). The sheath, composed of the TssB and TssC proteins, is the contractile structure that assembles in an extended, metastable conformation that stores the energy required to propulse the inner tube (44). By using time-lapse fluorescence microscopy, it has been shown that the assembly of the $600 \mathrm{~nm}$-long T6SS tube/sheath is completed in $\sim 20$ seconds and could be maintained in the extended conformation for several hundreds of seconds $(22,44)$. However, how the extended sheath is stably maintained requires further investigations. The atomic structure of the T6SS sheath in its contracted form has been solved by cryo-electron microscopy (Fig. 8F; 45-47). The sheath is a helical structure composed of 6$\mathrm{TssB} / \mathrm{Tss} \mathrm{C}$ heterodimer strands. Contacts between the heterodimers involve the formation of a 4 -stranded $\beta$-sheet handshake domain comprising two $\beta$-strands from $\mathrm{Tss} C$, one from the next TssC on the same strand, and one from TssB from the neighboring strand. This assembly mechanism therefore connects heterodimers of the same strand, as well as with that of the next strand (47). The contraction of the sheath is a fast event that occurs in less that $5 \mathrm{msec}$ (44). Although the propulsion of the inner tube or the delivery of effectors has not been imaged yet, the contraction of the sheath coincides with the lysis of the prey cell (Fig. 9; 22). Once contracted, an N-terminal helix of the TssC subunits protrudes from the structure and recruits the ClpV ATPase that will recycle the sheath subunits $(44,48-50)$.

\section{FUNCTION AND EFFECTORS}

The Type VI secretion system garnered interests due to its ability to target both eukaryotic and prokaryotic cells, therefore delivering toxins with a broad range of activities including nucleases, phospholipases, peptidoglycan hydrolases, $\mathrm{NAD}(\mathrm{P})^{+}$glycohydrolases or cytoskeleton remodeling enzymes (51-55). These toxins are independent polypeptides confined into the Hcp tail tube lumen or displayed at the tip of the VgrG needle via adaptor proteins, or covalently linked as additional C-terminal domains to VgrGs (41, 54, 56-62).

The Type VI secretion system recently emerged as one of the key players during bacterial pathogenesis. However, beside the fact that T6SS expression is usually co-regulated with virulence factors, the role of the T6SS in the infection process could be either direct or indirect. In a few instances, including in pathogenic strains of E. coli (see below), the T6SS has been shown to be directly involved in bacterial virulence such as mediating adhesion to host cells or participating to the survival into macrophages or to systemic proliferation, but the molecular details on how the apparatus - or specific secreted proteins - interferes with the host cells have not been defined. In V. cholerae, it has been shown that the T6SS disables macrophage by interfering with the dynamics of the cell cytoskeleton. This ability depends on the C-terminal domain carried by the VgrG1 spike, which possesses actin cross-linking activity, therefore curbing actin dynamics, preventing cell movement and inhibiting further phagocytosis of bacterial cells (63-65). The Aeromonas hydrophila VgrG1 C-terminal extension has been proposed to carry actin-targeting ADP-ribosyltransferase activity (66). Additional T6SS effectors with anti-host activities include phospholipases in Pseudomonas aeruginosa, and toxins that induce membrane fusion (such as the B. thailandensis and $B$. pseudomallei $\mathrm{VgrG} 5 \mathrm{C}$-terminal extensions) or interfere with microtubule dynamics (67-70). The direct role of the T6SS for virulence towards mammalian models of infection has been challenged by the discovery that the vast majority of T6SSs characterized so far are involved in bacterial growth inhibition. The T6SS is used to deliver anti-bacterial effectors with peptidoglycan hydrolase (amidase (Tae), glycoside hydrolase (Tge)) or phospholipase (Tle) activities into the periplasm of the target prey cell (71-74). These amidases, muramidases and phospholipases belongs to various families that hydrolyse bonds within the peptidic stems (Tae1-4 families) or glucosidic chains (Tge1-3 families) of the peptidoglycan or ester bonds 
of phospholipids (Tle1-5 families), respectively $(52-54,72,74)$. Toxins with nuclease (Tde) and $\mathrm{NAD}(\mathrm{P})^{+}$glycohydrolase activities have been reported and therefore should reach the cytoplasm for their action $(55,75,76)$. How these toxins are transported across the inner membrane is not clearly defined, but it has been proposed that the translational elongation factor $\mathrm{Tu}(\mathrm{EF}-\mathrm{Tu})$ contributes to the translocation of the $\mathrm{NAD}(\mathrm{P})^{+}$glycohydrolase in $P$. aeruginosa (55). Producing cells are protected from their own effectors or the effectors of their siblings by the co-production of specific protein inhibitors - or immunity proteins - that bind and inhibit the activity of the cognate toxins (52-54). $\mathrm{T}^{-} \mathrm{SS}^{+}$bacteria, including closely related species, carries different and unique sets of anti-bacterial effectors, supporting a leading role for T6SS effectors in inter- and intra-bacterial competition and in reshaping bacterial communities (52).

\section{Functions and Effectors in E. coli, Salmonella and related species}

\section{Phenotypes associated with T6SS in E. coli and Salmonella}

Most of the E. coli and Salmonella T6SSs studied so far have been shown to participate to adherence to biotic and abiotic surfaces, to bacterial competition or to virulence towards corresponding models of infection (Table 1). Taken together, the available information on $E$. coli T6SSs point to a role of T6SS-1 and T6SS-3 for anti-bacterial activity, and T6SS-2 for pathogenesis.

T6SS-dependent bellicose behaviors towards neighboring bacteria have been evidenced for EAEC 17-2 (T6SS-1 and T6SS-3; 22), APEC TW-XM (T6SS-1; 77) and Citrobacter rodentium (78). S. enterica Typhimurium LT2 has also been recently reported to have antagonistic activities against E. coli and Salmonella species in a SPI-6 T6SS-dependent manner (19). However, in S. enterica Typhimurium, the T6SS is up-regulated in the late stages of infection, once the bacterium is internalized in eukaryotic phagocytic cells whereas no up-regulation could be observed in mixed bacterial cultures $(17,19,79)$. These observations suggest that the anti-bacterial activity is activated inside the host. Interestingly, the T6SS is under a regulatory network that also regulates virulence factors including proliferation genes. Because the S. enterica Typhimurium population inside phagocytic cells is usually clonal, Brunet et al. proposed that the T6SS may serve to eliminate disabled $S$. enterica Typhimurium cells of the progeny, i.e., the cells unable to produce the T6SS immunity and proliferation genes (19).

A role of the T6SS for biofilm formation has been reported for EAEC 17-2 (T6SS-1; 28) and APEC SEPT362 (T6SS-2; 80). In APEC, the defect in biofilm is accompanied by decreased adherence to epithelial cells (80). However, it is likely that these phenotypes are caused by impacts on fimbriae gene regulation or by perturbations of the biofilm structure due to the anti-bacterial activity. Indeed, deletions of T6SS-2 genes in APEC SEPT362 affect the expression of type 1 fimbriae and flagella, two extracellular structures required for adhesion and biofilm formation $(80,81)$.

T6SS-dependent pathogenesis towards hosts has been tested for a number of strains (Table 1). From the available data, and in agreement with the over-representation of T6SS-2 in virulent strains, no defect in virulence have been noted for T6SS-1 or T6SS-3 mutants, whereas mutations in T6SS-2 gene clusters usually impact colonization, survival or invasion. The EAEC 17-2 T6SS-1 and T6SS-3 are not required for virulence towards $C$. elegans and intestinal survival within BALB/c mice respectively $(21,28)$ and mutants in the UPEC CFT073 T6SS-1 gene cluster do not present colonization defects in CBA/J mice bladders and kidneys (82). By contrast to T6SS-1 and T6SS-3, the APEC DE719 and SEPT362 T6SS-2 display attenuated virulence and decreased systemic dissemination in chicks or ducks, and reduced intracellular survival in chicken macrophage cells $(12,80)$. In APEC strain TW-XM, 
T6SS-2 is necessary for cerebral infection and penetration of the blood-brain barrier (11). Similarly, the MNEC K1 T6SS-2 is required for internalization in human brain microvascular endothelial cells (83). In MNEC K1, T6SS-2 carries two Hcp proteins. Analyses of the phenotypes of mutations in these two genes showed that Hcp 1 is required for efficient binding to brain endothelial cells whereas Hcp2 induces stress fiber formation, cytoskeleton rearrangements, cytokine and chemokine release and cell apoptosis via activation of the caspase 8 pathway (83). Therefore the function of this apparatus is necessary at two different stages of the infection process, probably by the Hcp1- and Hcp2-specific transport of distinct effectors. In Salmonella Typhi, the SPI-6 genes are required for systemic infection in a humanized mouse model (84) whereas conflicting data have been reported for the $S$. enterica Typhimurium SPI-6 T6SS regarding replication, survival and proliferation in macrophages or in mice $(17,79,85,86)$. However, the most important effect on replication within phagocytic cells is observed with the tai4 mutation, a gene that encodes the immunity to the Tae4 amidase, suggesting that this defect is indirect and due to self-intoxication caused by the loss of the immunity $(17,19)$. The S. enterica Gallinarum SPI-19 is required for survival and growth within chicken macrophages and for efficient colonization of the chick gastrointestinal tract and internal organs $(87,88)$. It is interesting to note that the phenotypes associated with the deletion of the SPI-6 T6SS gene cluster in S. enterica Typhimurium can be rescued by the expression of the S. enterica Gallinarum SPI-19 T6SS suggesting that both T6SSs perform similar functions despite their phylogenetic differences (89).

\section{E. coli and Salmonella T6SS toxins}

In E. coli and Salmonella strains, few effectors have been characterized in details, but their presence and putative activities can be easily predicted. They are organized in tandem with genes encoding small proteins that likely correspond to cognate immunity proteins. Furthermore, they usually co-occur with $h c p, \operatorname{vgr} G$ or paar genes. E. coli T6SS-1 gene clusters encode putative phospholipases (Table 1, Fig. 5A). They localize upstream the $\operatorname{vgrG}$ genes suggesting that, as shown for Vibrio cholerae (90), they use the VgrG needle as carrier for their transport. Interestingly, close inspection of these phospholipase genes suggest they belong to different families: while the AIEC LF82 or UPEC CFT073 T6SS-1 clusters carry putative phospholipases of the Tle3 family, those present on the EAEC 042 and APEC TW-XM genomes are closely related to phospholipases of the Tle1 and Tle4 families respectively (Fig. 5A; 77).

E. coli T6SS-2 gene clusters, as well as the S. enterica Gallinarum SPI-19 T6SS-2-like T6SS, usually contain genes encoding Rhs elements (Table 1), but the activity carried by these Rhs proteins can not be inferred from in silico prediction algorithms. In addition to the main T6SS gene cluster, S. enterica Gallinarum possesses an hcp island that encode an Hcp protein, an amidase of the Tae 3 family and its cognate Tai3 immunity $(15,73)$. No gene with putative toxin activity is found within E. coli T6SS-3 gene clusters.

The S. enterica Arizonae SPI-21 T6SS carries two pairs of S-type pyocins/immunity, as well as a specialized Hcp protein corresponding to a fusion between a traditional Hcp protein to an effector domain (15).

The $S$. enterica Typhimurium SPI-6 T6SS encodes Rhs elements as well as an amidase of the Tae4 family (73) (Table 1, Fig. 6). The structure of Tae4 is available, alone or in complex with its cognate Tai4 immunity protein $(91,92)$. Tae4 is a DL-endopeptidase with a typical NlpC/P60 domain. It hydrolyses the D-Glu/meso-diaminopimelic acid (mDAP) bond of peptidoglycan peptidic stems. A dimer of Tai4 binds to Tae 4 with a $K_{D}$ of $3 \times 10^{-10} \mathrm{M}$ and inhibits Tae4 activity by inserting the L4 protruding loop of one Tai4 monomer into the Tae4 catalytic pocket $(91,92)$. Contacts between Tae 4 and Tai 4 are stabilized by the $\alpha$-helix of the second Tai4 subunit $(91,92)$. A similar Tae4/Tai4 pair is encoded within the Enterobacter 
cloacae SPI-6-like T6SS (73). Indeed, cross-immunity between the S. enterica Typhimurium and E. cloacae Tae4/Tai4 pairs has been demonstrated (18). Finally, an original mechanism has been revealed in the case of the S. enterica Typhimurium Rhs (93). The gene encoding the 443 full-length Rhs protein ( $\mathrm{Rhs}^{\text {main }}$ ) is followed by a non-translated region encoding an orphan $\mathrm{C}$ terminal extension ( $\mathrm{Rhs}{ }^{\text {orphan }}$ ). However, serial passages in broth or within the mouse induces a duplication of the region and a genetic chromosomal re-arrangement that results to the production of a chimera Rhs protein constituted of the $\mathrm{Rhs}^{\text {main }}$ core and the $\mathrm{Rhs}{ }^{\text {orphan }} \mathrm{C}$ terminal extension with anti-bacterial activity. This elegant mechanism therefore provides a selective advantage to cells of the evolved bacterial lineage as it enables to maintain the immunity to Rhs ${ }^{\text {main }}$ and to deploy a new toxin that is active against ancestral cells (93).

Finally, two genes present within the Citrobacter freundii and E. cloacae T6SS gene clusters encode proteins with MIX domains, an N-terminal sequence associated with several T6SS toxins (94).

\section{REGULATORY MECHANISMS}

T6SS gene clusters are tightly regulated to adapt their expression to the environmental conditions. In agreement with the broad diversity of T6SS targets and activities, T6SS gene clusters are not submitted to a unique regulation but rather have hijacked most of the regulatory mechanisms known in bacteria, including that at the level of transcription or posttranscription $(20,95)$ : two-component systems, transcriptional activators and repressors, histone-like nucleoid associated proteins, quorum sensing, alternative sigma factors, small regulatory RNAs, etc. In addition, a post-translational phosphorylation-dependent pathway has been identified and characterized in Pseudomonads. This signal transmission involves sensing of specific stimuli and activation of a trans-envelope transducing cascade comprising the TagFQRST proteins and leading to the PpkA-dependent phosphorylation of the forkheadassociated FHA protein (96-100). The reversibility of the activation is secured by the dephosphorylation of FHA by the PppA phosphatase (96).

\section{Regulation of T6SS gene clusters in E. coli, Salmonella and related species}

\section{Transcriptional regulation}

T6SSs have been studied in details in Pseudomonas, Agrobacterium and Vibrio species. Hence, we have a comprehensive picture of the regulatory mechanisms underlying expression of the T6SS gene clusters in these bacteria. By contrast, except for the entero-aggregative $E$. coli and S. enterica Typhimurium T6SSs, only very few is know on the regulation of T6SSs in other E. coli and Salmonella serotypes.

Enteroaggregative E. coli. The EAEC 17-2 strain genome encodes two complete sets of T6SS genes (families T6SS-1 and T6SS-3). The T6SS-1 family cluster (also called sci-1) is under the control of the Fur repressor (23, Fig. 10). Fur - for Ferric uptake regulator - is the main regulator that couples iron homeostasis to gene expression (101). In presence of iron, Fur binds to two Fur boxes present in tandem in the promoter sequence of this cluster, overlapping with the transcriptional $-10\left(\mathrm{Fur}^{-10}\right)$ and $-35\left(\mathrm{Fur}^{-35}\right)$, preventing RNA polymerase recruitment and therefore turning OFF the T6SS-1 genes (23). This very simple mechanism is complexified by an epigenetic circuit depending on the action of the Dam adenosine methyltransferase, which couples T6SS expression to the replication state. The Fur ${ }^{-10}$ box contains a GATC motif that is recognized and methylated by Dam. When Fur is bound to the Fur $^{-10}$ box, the site is not methylated. However, under low iron conditions, Fur is dislodged, the T6SS- 1 genes are turned ON. If cells replicate, the Fur $^{-10}$ box is methylated after the first 
replication, preventing Fur to bind back, therefore turning the T6SS genes under a constitutive ON state. Fur therefore controls the passage between the OFF and ON states whereas Dam is a sensor of replication and controls the passage between the reversible and constitutive ON states (23) (Fig. 10). In agreement with these data, the EAEC T6SS-1 is activated in minimal media or in iron depletion conditions (24). However, this mechanism is unlikely to be conserved between the T6SS-1 clusters shared by pathogenic E. coli as no Fur box could be readily identified in their promoter regions. The EAEC T6SS-3 gene cluster (also called sci-2 or aai) is activated in synthetic media mimicking the macrophage environment such as Eagle's medium $(21,22)$. DNA microarrays and quantitative RT-PCR have demonstrated that this activation depends on an AraC-like transcriptional regulator called $\operatorname{AggR}(21,102)$. Although no consensus binding site has been defined for AggR, this activator regulates other EAEC virulence factors such as the Aaf fimbriae, the dispersin and the dispersin transporter (102).

503 No data are available yet for the T6SS-2 gene cluster found in the EAEC 042 strain. Although it remains to be experimentally tested, it has been proposed that regulation of the T6SS-2 EC042_0229 gene involves the synergistical action of the cyclic AMP receptor protein (CRP) and the nucleoid-associated protein Fis by an original mechanism requiring Fis-dependent compensation of the non-optimal spacing between the CRP and RNA polymerase binding sites (103).

Salmonella enterica. In S. enterica Typhimurium LT2, the SPI-6 T6SS gene cluster is controlled by the SsrA/B Two-component system, one of the major regulatory pathways of Salmonella virulence (79). The SsrB response regulator binds to and positively regulates most SPI-2 promoters including those controlling expression of the T3SS genes (104). By contrast, SsrA/B exerts a negative control on the SPI-6 T6SS gene cluster $(17,79)$, probably by direct SsrB binding on distinct promoter regions (105). The expression of T6SS genes encoded within the SPI-6 pathogenicity island are not detected under laboratory in vitro conditions (79, 106); however, promoter reporter and transcriptional profiling studies showed that the expression of these genes is activated in the late stages of macrophage and epithelial cells infection $(17,107)$. In addition to SsrB, the SPI-6 T6SS genes are silenced by the histone-like nucleoid structuring H-NS protein $(19,108,109)$. H-NS binds to A/T-rich motifs and polymerizes to spread and silence the genes by preventing access to the RNA polymerase or activators. H-NS is thus a xenogenic silencer that usually represses horizontally-acquired genes and islands (110). Because T6SS genes are clustered in these islands, H-NS is probably involved in the regulation of many T6SS gene clusters in pathogenic E. coli but this needs to be addressed.

In S. enterica Typhi Ty2, several regulators have been identified such as RcsB, PmrA and Hfq, but their contribution for the activation of the T6SS genes is relatively weak (111). In Enterobacter cloacae, several genes of the T6SS cluster are under the control of a LuxR/acylhomoserine lactone-dependent quorum sensing mechanism and therefore respond to the population density (112).

In addition to the EAEC T6SS-3 cluster, shown to be induced in media mimicking the macrophage environment, most of the E. coli and Salmonella T6SS genes are induced in in vivo conditions. This has been reported for the S. enterica Typhimurium SPI-6 T6SS genes, which are upregulated during macrophage infection $(79,107)$ and for the S. enterica Gallinarum SPI-19 T6SS genes which are upregulated after internalization by murine or avian macrophages (87). These data suggest that these T6SS gene clusters might play a direct role during infection or that host-mediated activation of the anti-bacterial activity might help to clear the niche and to enable efficient colonization. 
In Citrobacter rodentium, the tss $M$ gene is subjected to transcriptional frameshifting. The tss $M$ gene is interrupted by a premature stop codon, but a poly-A slippery tract located upstream the stop codon induces incorporation of additional adenosines in the RNA and hence the synthesis of TssM length variants (113). Yet, whether the frameshifting efficiency is influenced by environmental cues or by regulatory factors is unknown.

Finally, it is interesting to note that genes encoding the phosphorylation-dependent posttranslational pathway found in Pseudomonas and Agrobacterium species are present in none of the E. coli, Salmonella, Citrobacter or Enterobacter strain genomes sequenced so far, except for those encoding FHA proteins which are found associated with E. coli T6SS-2-like and Salmonella SPI-19 clusters (Fig. 5B and Fig. 6). However, the contribution of FHA for the assembly or the activation of the system has not been reported in these strains.

\section{ACKNOWLEDGMENTS}

This chapter summarizes the current knowledge on the T6SSs present in E. coli and related species. It is clear that the recent years have provided a detailed view on the architecture and mechanism of assembly of this apparatus. However, the regulatory mechanisms underlying the expression of these gene clusters, the effectors delivered by this machinery and the function of the T6SS during host infection remain enigmatic for most enterobacterial pathogens. Further studies will provide a better understanding of the T6SS contribution in the ecological niche of these strains or for pathogenesis. Similarly, although a number of antibacterial effectors with amidase, peptidoglycan hydrolase, phospholipase and DNase activities have been identified or predicted, it remains to determine whether phospholipases and DNases might be targeted into eukaryotic host cells and to identify anti-eukaryoticspecific effectors. These toxins would be therefore interesting targets for the development of drugs that will interfere with these toxins, not only for human health, but also in the cases in which the bacterial pathogen targets poultry or cattle.

We thank Yannick R. Brunet for generating the time-lapse recordings shown in Fig. 2, the past and present members of the Cascales group for insightful discussions and Andy Vojeambont for encouragements. We apologize for omissions of primary works owing to space constraints. Work in E.C. laboratory is supported by the Centre National de la Recherche Scientifique, the Aix-Marseille Université, doctoral and post-doctoral fellowships from the French Ministère de la Recherche and the Fondation pour la Recherche Médicale, and grants from the Agence Nationale de la Recherche (ANR-10-JCJC-1303-03 and ANR-14CE14-0006-02).

\section{REFERENCES}

1. Bingle LE, Bailey CM, Pallen MJ. 2008. Type VI secretion: a beginner's guide. Curr Opin Microbiol. 11:3-8.

590 2. Boyer F, Fichant G, Berthod J, Vandenbrouck Y, Attree I. 2009. Dissecting the bacterial type 
591 VI secretion system by a genome wide in silico analysis: what can be learned from available microbial 592 genomic resources? BMC Genomics. 10:104.

593 3. Coulthurst SJ. 2013. The Type VI secretion system - a widespread and versatile cell targeting 594 system. Res Microbiol. 164:640-54.

4. Zoued A, Brunet YR, Durand E, Aschtgen MS, Logger L, Douzi B, Journet L, Cambillau C, Cascales E. 2014. Architecture and assembly of the Type VI secretion system. Biochim Biophys Acta. 1843:1664-73. type VI secretion-related pathway in Bacteroidetes mediates interbacterial antagonism. Cell Host Microbe. 16:227-36.

6. Cascales E. 2008. The type VI secretion toolkit. EMBO Rep. 9:735-41.

7. Silverman JM, Brunet YR, Cascales E, Mougous JD. 2012. Structure and regulation of the type VI secretion system. Annu Rev Microbiol. 66:453-72.

8. Ho BT, Dong TG, Mekalanos JJ. 2014. A view to a kill: the bacterial type VI secretion system. Cell Host Microbe. 15:9-21.

607 9. Basler M. 2015. Type VI secretion system: secretion by a contractile nanomachine. Philos Trans $R$ 608 Soc Lond B Biol Sci.370:1679-1691.

10. Cascales E, Cambillau C. 2012. Structural biology of type VI secretion systems. Philos Trans $R$ Soc Lond B Biol Sci.367:1102-11.

11. Ma, J., M. Sun, Y. Bao, Z. Pan, W. Zhang, C. Lu, and H. Yao. 2013. Genetic diversity and features analysis of type VI secretion systems loci in avian pathogenic Escherichia coli by wide genomic scanning. Infect Genet Evol 20:454-64.

12. Wang S, Dai J, Meng Q, Han X, Han Y, Zhao Y, Yang D, Ding C, Yu S. 2014. DotU expression is highly induced during in vivo infection and responsible for virulence and Hcp1 secretion in avian pathogenic Escherichia coli. Front Microbiol. 5:588. Infect Dis. 171:465-8. improved genome-scale reconstruction of E. coli. BMC Genomics 12:9. uncovers 3 novel loci encoding type six secretion systems differentially distributed in Salmonella serotypes. BMC Genomics. 10:354. 
17. Mulder DT, Cooper CA, Coombes BK. 2012. Type VI secretion system-associated gene clusters contribute to pathogenesis of Salmonella enterica serovar Typhimurium. Infect Immun. 80:1996-2007.

18. Zhang H, Gao ZQ, Wei Y, Xu JH, Dong YH. 2013. Insights into the cross-immunity mechanism within effector families of bacteria type VI secretion system from the structure of StTae4-EcTai4 complex. PLoS One. 8: 73782.

636

637

638

19. Brunet YR, Khodr A, Logger L, Aussel L, Mignot T, Rimsky S, Cascales E. 2015. H-NS silencing of the Salmonella pathogenicity island 6-encoded type VI secretion system limits Salmonella enterica eerovar Typhimurium interbacterial killing. Infect Immun. 83:2738-50.

20. Bernard CS, Brunet YR, Gueguen E, Cascales E. 2010. Nooks and crannies in type VI secretion regulation. $J$ Bacteriol. 192:3850-60.

21. Dudley EG, Thomson NR, Parkhill J, Morin NP, Nataro JP. 2006. Proteomic and microarray characterization of the AggR regulon identifies a pheU pathogenicity island in enteroaggregative Escherichia coli. Mol Microbiol. 61:1267-82.

22. Brunet YR, Espinosa L, Harchouni S, Mignot T, Cascales E. 2013. Imaging type VI secretionmediated bacterial killing. Cell Rep. 3:36-41.

23. Brunet YR, Bernard CS, Gavioli M, Lloubès R, Cascales E. 2011. An epigenetic switch involving overlapping fur and DNA methylation optimizes expression of a type VI secretion gene cluster. PLoS Genet. 7:e1002205.

24. Zoued A, Durand E, Bebeacua C, Brunet YR, Douzi B, Cambillau C, Cascales E, Journet L. 2013. TssK is a trimeric cytoplasmic protein interacting with components of both phage-like and membrane anchoring complexes of the type VI secretion system. J Biol Chem. 288:27031-41.

25. Brunet YR, Zoued A, Boyer F, Douzi B, Cascales E. 2015. The Type VI secretion TssEFGKVgrG phage-like baseplate is recruited to the TssJLM membrane complex via multiple contacts and serves as assembly platform for tail tube/sheath polymerization. PLOS Genetics. 11:e1005545.

26. Durand E, Nguyen VS, Zoued A, Logger L, Péhau-Arnaudet G, Aschtgen MS, Spinelli S, Desmyter A, Bardiaux B, Dujeancourt A, Roussel A, Cambillau C, Cascales E, Fronzes R. 2015. Biogenesis and structure of a type VI secretion membrane core complex. Nature. 523:555-60.

27. Aschtgen MS, Gavioli M, Dessen A, Lloubès R, Cascales E. 2010. The SciZ protein anchors the enteroaggregative Escherichia coli Type VI secretion system to the cell wall. Mol Microbiol. 75:88699.

28. Aschtgen MS, Bernard CS, de Bentzmann S, Lloubès R, Cascales E. 2008. SciN is an outer membrane lipoprotein required for type VI secretion in enteroaggregative Escherichia coli. $J$ Bacteriol. 190:7523-31.

29. Ma LS, Lin JS, Lai EM. 2009. An IcmF family protein, $\operatorname{ImpL}_{\mathrm{M}}$, is an integral inner membrane protein interacting with $\operatorname{ImpK}_{\mathrm{L}}$, and its walker a motif is required for type VI secretion systemmediated Hcp secretion in Agrobacterium tumefaciens. J Bacteriol. 191:4316-29.

30. Felisberto-Rodrigues C, Durand E, Aschtgen MS, Blangy S, Ortiz-Lombardia M, Douzi B, Cambillau C, Cascales E. 2011. Towards a structural comprehension of bacterial type VI secretion 
systems: characterization of the TssJ-TssM complex of an Escherichia coli pathovar. PLoS Pathog. 7:e1002386.

31. Nguyen VS, Logger L, Spinelli S, Desmyter A, Le TT, Kellenberger C, Douzi B, Durand E, Roussel A, Cascales E, Cambillau C. 2015. Inhibition of type VI secretion by an anti-TssM llama nanobody. PLoS One. 10:e122187.

674

675

676

677

678

679

680

681

682

683

684

685

686

687

688

689

690

691

692

693

694

695

696

697

698

699

700

701

702

703

704

705

706

32. Aschtgen MS, Zoued A, Lloubès R, Journet L, Cascales E. 2012. The C-tail anchored TssL subunit, an essential protein of the enteroaggregative Escherichia coli Sci-1 Type VI secretion system, is inserted by YidC. Microbiologyopen. 1:71-82.

33. Durand E, Zoued A, Spinelli S, Watson PJ, Aschtgen MS, Journet L, Cambillau C, Cascales E. 2012. Structural characterization and oligomerization of the TssL protein, a component shared by bacterial type VI and type IVb secretion systems. J Biol Chem. 287:14157-68.

34. Aschtgen MS, Thomas MS, Cascales E. 2010. Anchoring the type VI secretion system to the peptidoglycan: TssL, TagL, TagP... what else? Virulence. 1:535-40.

35. Ma LS, Narberhaus F, Lai EM. 2012. IcmF family protein TssM exhibits ATPase activity and energizes type VI secretion. J Biol Chem. 287:15610-21.

36. Leiman PG, Arisaka F, van Raaij MJ, Kostyuchenko VA, Aksyuk AA, Kanamaru S, Rossmann MG. 2010. Morphogenesis of the T4 tail and tail fibers. Virol J. 7:355.

37. Lossi NS, Dajani R, Freemont P, Filloux A. 2011. Structure-function analysis of HsiF, a gp25like component of the type VI secretion system, in Pseudomonas aeruginosa. Microbiology. 157:3292-305.

38. English G, Byron O, Cianfanelli FR, Prescott AR, Coulthurst SJ. 2014. Biochemical analysis of TssK, a core component of the bacterial Type VI secretion system, reveals distinct oligomeric states of TssK and identifies a TssK-TssFG subcomplex. Biochem J. 461:291-304.

39. Leiman PG, Basler M, Ramagopal UA, Bonanno JB, Sauder JM, Pukatzki S, Burley SK, Almo SC, Mekalanos JJ. 2009. Type VI secretion apparatus and phage tail-associated protein complexes share a common evolutionary origin. Proc Natl Acad Sci USA. 106:4154-9.

40. Uchida K, Leiman PG, Arisaka F, Kanamaru S. 2014. Structure and properties of the Cterminal $\beta$-helical domain of VgrG protein from Escherichia coli O157. J Biochem. 155:173-82.

41. Shneider MM, Buth SA, Ho BT, Basler M, Mekalanos JJ, Leiman PG. 2013. PAAR-repeat proteins sharpen and diversify the type VI secretion system spike. Nature. 500:350-3.

42. Douzi B, Spinelli S, Blangy S, Roussel A, Durand E, Brunet YR, Cascales E, Cambillau C. 2014. Crystal structure and self-interaction of the type VI secretion tail-tube protein from enteroaggregative Escherichia coli. PLoS One. 9:e86918.

43. Brunet YR, Hénin J, Celia H, Cascales E. 2014. Type VI secretion and bacteriophage tail tubes share a common assembly pathway. EMBO Rep. 15:315-21.

44. Basler M, Pilhofer M, Henderson GP, Jensen GJ, Mekalanos JJ. 2012. Type VI secretion requires a dynamic contractile phage tail-like structure. Nature. 483:182-6.

45. Kube S, Kapitein N, Zimniak T, Herzog F, Mogk A, Wendler P. 2014. Structure of the VipA/B 
type VI secretion complex suggests a contraction-state-specific recycling mechanism. Cell Rep. 8:2030.

46. Clemens DL, Ge P, Lee BY, Horwitz MA, Zhou ZH. 2015. Atomic structure of T6SS reveals interlaced array essential to function. Cell. 160:940-51.

47. Kudryashev M, Wang RY, Brackmann M, Scherer S, Maier T, Baker D, DiMaio F, Stahlberg H, Egelman EH, Basler M. 2015. Structure of the type VI secretion system contractile sheath. Cell. 160:952-62.

48. Bönemann G, Pietrosiuk A, Diemand A, Zentgraf H, Mogk A. 2009. Remodelling of VipA/VipB tubules by ClpV-mediated threading is crucial for type VI protein secretion. EMBO J. 716 28:315-25

49. Pietrosiuk A, Lenherr ED, Falk S, Bönemann G, Kopp J, Zentgraf H, Sinning I, Mogk A. 2011. Molecular basis for the unique role of the AAA+ chaperone ClpV in type VI protein secretion. $J$ Biol Chem. 286:30010-21.

50. Kapitein N, Bönemann G, Pietrosiuk A, Seyffer F, Hausser I, Locker JK, Mogk A. 2013. $\mathrm{ClpV}$ recycles $\mathrm{VipA} / \mathrm{VipB}$ tubules and prevents non-productive tubule formation to ensure efficient 722 type VI protein secretion. Mol Microbiol. 87:1013-28.

51. Schwarz S, Hood RD, Mougous JD. 2010. What is type VI secretion doing in all those bugs? Trends Microbiol. 18:531-7.

52. Russell AB, Peterson SB, Mougous JD. 2014. Type VI secretion system effectors: poisons with a purpose. Nat Rev Microbiol. 12:137-48.

53. Benz J, Meinhart A. 2014. Antibacterial effector/immunity systems: it's just the tip of the iceberg. Curr Opin Microbiol. 17:1-10.

54. Durand E, Cambillau C, Cascales E, Journet L. 2014. VgrG, Tae, Tle, and beyond: the versatile arsenal of Type VI secretion effectors. Trends Microbiol. 22:498-507.

55. Whitney JC, Quentin D, Sawai S, LeRoux M, Harding BN, Ledvina HE, Tran BQ, Robinson H, Goo YA, Goodlett DR, Raunser S, Mougous JD. 2015. An interbacterial NAD $(\mathrm{P})^{+}$ glycohydrolase toxin requires elongation factor Tu for delivery to target cells. Cell. in press

56. Alcoforado Diniz J, Liu YC, Coulthurst SJ. 2015. Molecular weaponry : diverse effectors delivered by the Type VI secretion system. Cell Microbiol. in press.

736

737

738

739

740

741

742

743

744
57. Pukatzki S, Ma AT, Revel AT, Sturtevant D, Mekalanos JJ. 2007. Type VI secretion system translocates a phage tail spike-like protein into target cells where it cross-links actin. Proc Natl Acad Sci USA. 104:15508-13.

58. Silverman JM, Agnello DM, Zheng H, Andrews BT, Li M, Catalano CE, Gonen T, Mougous JD. 2013. Haemolysin coregulated protein is an exported receptor and chaperone of type VI secretion substrates. Mol Cell. 51:584-93.

59. Whitney JC, Beck CM, Goo YA, Russell AB, Harding BN, De Leon JA, Cunningham DA, Tran BQ, Low DA, Goodlett DR, Hayes CS, Mougous JD. 2014. Genetically distinct pathways guide effector export through the type VI secretion system. Mol Microbiol. 92:529-42. 
60. Alcoforado Diniz J, Coulthurst SJ. 2015. Intraspecies competition in Serratia marcescens is mediated by type VI-secreted Rhs effectors and a conserved effector-associated accessory protein. $J$ Bacteriol. 197:2350-60.

61. Liang X, Moore R, Wilton M, Wong MJ, Lam L, Dong TG. 2015. Identification of divergent type VI secretion effectors using a conserved chaperone domain. Proc Natl Acad Sci USA. 112:910611.

62. Unterweger D, Kostiuk B, Ötjengerdes R, Wilton A, Diaz-Satizabal L, Pukatzki S. 2015. Chimeric adaptor proteins translocate diverse type VI secretion system effectors in Vibrio cholerae. $E M B O J$. in press.

63. Pukatzki S, Ma AT, Revel AT, Sturtevant D, Mekalanos JJ. 2007. Type VI secretion system translocates a phage tail spike-like protein into target cells where it cross-links actin. Proc Natl Acad Sci USA. 104:15508-13.

64. Ma AT, McAuley S, Pukatzki S, Mekalanos JJ. 2009. Translocation of a Vibrio cholerae type VI secretion effector requires bacterial endocytosis by host cells. Cell Host Microbe. 5:234-43.

65. Durand E, Derrez E, Audoly G, Spinelli S, Ortiz-Lombardia M, Raoult D, Cascales E, Cambillau C. 2012. Crystal structure of the VgrG1 actin cross-linking domain of the Vibrio cholerae type VI secretion system. J Biol Chem. 287:38190-9.

66. Suarez G, Sierra JC, Erova TE, Sha J, Horneman AJ, Chopra AK. 2010. A type VI secretion system effector protein, VgrG1, from Aeromonas hydrophila that induces host cell toxicity by ADP ribosylation of actin. J Bacteriol. 192:155-68.

67. Jiang F, Waterfield NR, Yang J, Yang G, Jin Q. 2014. A Pseudomonas aeruginosa type VI secretion phospholipase D effector targets both prokaryotic and eukaryotic cells. Cell Host Microbe. 15:600-10.

68. Schwarz S, Singh P, Robertson JD, LeRoux M, Skerrett SJ, Goodlett DR, West TE, Mougous JD. 2014. VgrG-5 is a Burkholderia type VI secretion system-exported protein required for multinucleated giant cell formation and virulence. Infect Immun. 82:1445-52.

69. Toesca IJ, French CT, Miller JF. 2014. The Type VI secretion system spike protein VgrG5 mediates membrane fusion during intercellular spread by pseudomallei group Burkholderia species. Infect Immun. 82:1436-44.

70. Sana TG, Baumann C, Merdes A, Soscia C, Rattei T, Hachani A, Jones C, Bennett KL, Filloux A, Superti-Furga G, Voulhoux R, Bleves S. 2015. Internalization of Pseudomonas aeruginosa strain PAO1 into epithelial cells is promoted by interaction of a T6SS effector with the microtubule network. MBio. 6:e00712.

71. Hood RD, Singh P, Hsu F, Güvener T, Carl MA, Trinidad RR, Silverman JM, Ohlson BB, Hicks KG, Plemel RL, Li M, Schwarz S, Wang WY, Merz AJ, Goodlett DR, Mougous JD. 2010. A type VI secretion system of Pseudomonas aeruginosa targets a toxin to bacteria. Cell Host Microbe. 7:25-37.

72. Russell AB, Hood RD, Bui NK, LeRoux M, Vollmer W, Mougous JD. 2011. Type VI secretion delivers bacteriolytic effectors to target cells. Nature. 475:343-7.

73. Russell AB, Singh P, Brittnacher M, Bui NK, Hood RD, Carl MA, Agnello DM, Schwarz S, 
Goodlett DR, Vollmer W, Mougous JD. 2012. A widespread bacterial type VI secretion effector superfamily identified using a heuristic approach. Cell Host Microbe. 11:538-49.

74. Russell AB, LeRoux M, Hathazi K, Agnello DM, Ishikawa T, Wiggins PA, Wai SN, Mougous JD. 2013. Diverse type VI secretion phospholipases are functionally plastic antibacterial effectors. Nature. 496:508-12.

75. Koskiniemi S, Lamoureux JG, Nikolakakis KC, t'Kint de Roodenbeke C, Kaplan MD, Low DA, Hayes CS. 2013. Rhs proteins from diverse bacteria mediate intercellular competition. Proc Natl Acad Sci USA. 110:7032-7.

76. Ma LS, Hachani A, Lin JS, Filloux A, Lai EM. 2014. Agrobacterium tumefaciens deploys a superfamily of type VI secretion DNase effectors as weapons for interbacterial competition in planta. Cell Host Microbe. 16:94-104.

77. Ma J, Bao Y, Sun M, Dong W, Pan Z, Zhang W, Lu C, Yao H. 2014. Two functional type VI secretion systems in avian pathogenic Escherichia coli are involved in different pathogenic pathways. Infect Immun. 82:3867-79.

78. Gueguen E, Cascales E. 2013. Promoter swapping unveils the role of the Citrobacter rodentium CTS1 type VI secretion system in interbacterial competition. Appl Environ Microbiol. 79:32-8.

79. Parsons DA, Heffron F. 2005. sciS, an icmF homolog in Salmonella enterica serovar Typhimurium, limits intracellular replication and decreases virulence. Infect Immun. 73:4338-45.

80. de Pace F, Nakazato G, Pacheco A, de Paiva JB, Sperandio V, da Silveira WD. 2010. The type VI secretion system plays a role in type 1 fimbria expression and pathogenesis of an avian pathogenic Escherichia coli strain. Infect Immun. 78:4990-8.

81. de Pace F, Boldrin de Paiva J, Nakazato G, Lancellotti M, Sircili MP, Guedes Stehling E, Dias da Silveira W, Sperandio V. 2011. Characterization of IcmF of the type VI secretion system in an avian pathogenic Escherichia coli (APEC) strain. Microbiology. 157:2954-62.

82. Lloyd AL, Henderson TA, Vigil PD, Mobley HL. 2009. Genomic islands of uropathogenic Escherichia coli contribute to virulence. J Bacteriol. 191:3469-81.

83. Zhou Y, Tao J, Yu H, Ni J, Zeng L, Teng Q, Kim KS, Zhao GP, Guo X, Yao Y. 2012. Hcp family proteins secreted via the type VI secretion system coordinately regulate Escherichia coli K1 interaction with human brain microvascular endothelial cells. Infect Immun. 80:1243-51.

84. Libby SJ, Brehm MA, Greiner DL, Shultz LD, McClelland M, Smith KD, Cookson BT, Karlinsey JE, Kinkel TL, Porwollik S, Canals R, Cummings LA, Fang FC. 2010. Humanized nonobese diabetic-scid IL2r gammanull mice are susceptible to lethal Salmonella Typhi infection. Proc Natl Acad Sci USA. 107:15589-94.

85. Klumpp J, Fuchs TM. 2007. Identification of novel genes in genomic islands that contribute to Salmonella typhimurium replication in macrophages. Microbiology. 153:1207-20.

86. Liu J, Guo JT, Li YG, Johnston RN, Liu GR, Liu SL. 2013. The type VI secretion system gene cluster of Salmonella typhimurium: required for full virulence in mice. J Basic Microbiol. 53:600-7.

87. Blondel CJ, Jiménez JC, Leiva LE, Alvarez SA, Pinto BI, Contreras F, Pezoa D, Santiviago CA, Contreras I. 2013. The type VI secretion system encoded in Salmonella pathogenicity island 19 
is required for Salmonella enterica serotype Gallinarum survival within infected macrophages. Infect

Immun. 81:1207-20.

88. Blondel CJ, Yang HJ, Castro B, Chiang S, Toro CS, Zaldívar M, Contreras I, AndrewsPolymenis HL, Santiviago CA. 2010. Contribution of the type VI secretion system encoded in SPI19 to chicken colonization by Salmonella enterica serotypes Gallinarum and Enteritidis. PLoS One. 5:e11724.

830

831

832

833

834

835

836

837

838

839

840

841

842

843

844

845

846

847

848

849

850

851

852

853

854

855

856

857

858

859

860

861

862

89. Pezoa D, Yang HJ, Blondel CJ, Santiviago CA, Andrews-Polymenis HL, Contreras I. 2013. The type VI secretion system encoded in SPI-6 plays a role in gastrointestinal colonization and systemic spread of Salmonella enterica serovar Typhimurium in the chicken. PLoS One. 8:e63917.

90. Dong TG, Ho BT, Yoder-Himes DR, Mekalanos JJ. Identification of T6SS-dependent effector and immunity proteins by Tn-seq in Vibrio cholerae. Proc Natl Acad Sci USA. 110:2623-8.

91. Zhang H, Zhang H, Gao ZQ, Wang WJ, Liu GF, Xu JH, Su XD, Dong YH. 2013. Structure of the type VI effector-immunity complex (Tae4-Tai4) provides novel insights into the inhibition mechanism of the effector by its immunity protein. J Biol Chem. 288:5928-39.

92. Benz J, Reinstein J, Meinhart A. 2013. Structural insights into the effector-immunity system Tae4/Tai4 from Salmonella typhimurium. PLoS One. 8:e67362.

93. Koskiniemi S, Garza-Sánchez F, Sandegren L, Webb JS, Braaten BA, Poole SJ, Andersson DI, Hayes CS, Low DA. 2014. Selection of orphan Rhs toxin expression in evolved Salmonella enterica serovar Typhimurium. PLoS Genet. 10:e1004255.

94. Salomon D, Kinch LN, Trudgian DC, Guo X, Klimko JA, Grishin NV, Mirzaei H, Orth K. 2014. Marker for type VI secretion system effectors. Proc. Natl. Acad. Sc. USA. 111:9271-76.

95. Leung KY, Siame BA, Snowball H, Mok YK. 2011. Type VI secretion regulation: crosstalk and intracellular communication. Curr Opin Microbiol. 14:9-15.

96. Mougous JD, Gifford CA, Ramsdell TL, Mekalanos JJ. 2007. Threonine phosphorylation posttranslationally regulates protein secretion in Pseudomonas aeruginosa. Nat Cell Biol. 9:797-803.

97. Hsu F, Schwarz S, Mougous JD. 2009. TagR promotes PpkA-catalysed type VI secretion activation in Pseudomonas aeruginosa. Mol Microbiol. 72:1111-25.

98. Silverman JM, Austin LS, Hsu F, Hicks KG, Hood RD, Mougous JD. 2011. Separate inputs modulate phosphorylation-dependent and -independent type VI secretion activation. Mol Microbiol. 82:1277-90.

99. Casabona MG, Silverman JM, Sall KM, Boyer F, Couté Y, Poirel J, Grunwald D, Mougous JD, Elsen S, Attree I. 2013. An ABC transporter and an outer membrane lipoprotein participate in posttranslational activation of type VI secretion in Pseudomonas aeruginosa. Environ Microbiol. 15:471-86.

100. Lin JS, Wu HH, Hsu PH, Ma LS, Pang YY, Tsai MD, Lai EM. 2014. Fha interaction with phosphothreonine of TssL activates type VI secretion in Agrobacterium tumefaciens. PLoS Pathog. 10:e1003991.

101. Escolar L, Pérez-Martín J, de Lorenzo V. 1999. Opening the iron box: transcriptional metalloregulation by the Fur protein. J Bacteriol. 181:6223-9. 
102. Morin N, Santiago AE, Ernst RK, Guillot SJ, Nataro JP. 2013. Characterization of the AggR regulon in enteroaggregative Escherichia coli. Infect Immun. 81:122-32.

103. Rossiter AE, Browning DF, Leyton DL, Johnson MD, Godfrey RE, Wardius CA, Desvaux M, Cunningham AF, Ruiz-Perez F, Nataro JP, Busby SJ, Henderson IR. 2011. Transcription of the plasmid-encoded toxin gene from enteroaggregative Escherichia coli is regulated by a novel coactivation mechanism involving CRP and Fis. Mol Microbiol. 81:179-91.

869

870

871

872

873

874

875

876

877

878

879

880

881

882

883

884

885

886

887

888

889

890

891

892

893

894

895

896

897

898

899

900

901

902
104. Fass E, Groisman EA. 2009. Control of Salmonella pathogenicity island-2 gene expression. Curr Opin Microbiol. 12:199-204.

105. Tomljenovic-Berube AM, Mulder DT, Whiteside MD, Brinkman FS, Coombes BK. 2010. Identification of the regulatory logic controlling Salmonella pathoadaptation by the SsrA-SsrB twocomponent system. PLoS Genet. 6:e1000875.

106. Kröger C, Dillon SC, Cameron AD, Papenfort K, Sivasankaran SK, Hokamp K, Chao Y, Sittka A, Hébrard M, Händler K, Colgan A, Leekitcharoenphon P, Langridge GC, Lohan AJ, Loftus B, Lucchini S, Ussery DW, Dorman CJ, Thomson NR, Vogel J, Hinton JC. 2012. The transcriptional landscape and small RNAs of Salmonella enterica serovar Typhimurium. Proc Natl Acad Sci USA. 109:E1277-86.

107. Hautefort I, Thompson A, Eriksson-Ygberg S, Parker ML, Lucchini S, Danino V, Bongaerts RJ, Ahmad N, Rhen M, Hinton JC. 2008. During infection of epithelial cells Salmonella enterica serovar Typhimurium undergoes a time-dependent transcriptional adaptation that results in simultaneous expression of three type 3 secretion systems. Cell Microbiol. 10:958-84.

108. Navarre WW, Porwollik S, Wang Y, McClelland M, Rosen H, Libby SJ, Fang FC. 2006. Selective silencing of foreign DNA with low GC content by the H-NS protein in Salmonella. Science. 313:236-8.

109. Lucchini S, Rowley G, Goldberg MD, Hurd D, Harrison M, Hinton JC. 2006. H-NS mediates the silencing of laterally acquired genes in bacteria. PLoS Pathog. 2:e81.

110. Navarre WW, McClelland M, Libby SJ, Fang FC. 2007. Silencing of xenogeneic DNA by HNS-facilitation of lateral gene transfer in bacteria by a defense system that recognizes foreign DNA. Genes Dev. 21:1456-71.

111. Wang M, Luo Z, Du H, Xu S, Ni B, Zhang H, Sheng X, Xu H, Huang X. 2011. Molecular characterization of a functional type VI secretion system in Salmonella enterica serovar Typhi. Curr Microbiol. 63:22-31.

112. Sabag-Daigle A, Dyszel JL, Gonzalez JF, Ali MM, Ahmer BM. 2015. Identification of sdiAregulated genes in a mouse commensal strain of Enterobacter cloacae. Front Cell Infect Microbiol. 5:47.

113. Gueguen E, Wills NM, Atkins JF, Cascales E. 2014. Transcriptional frameshifting rescues Citrobacter rodentium type VI secretion by the production of two length variants from the prematurely interrupted $t s s M$ gene. PLoS Genet. 10:e1004869.

114. Li J, Yao Y, Xu HH, Hao L, Deng Z, Rajakumar K, Ou HY. 2015. SecReT6: a web-based resource for type VI secretion systems found in bacteria. Environ Microbiol.17:2196-202. 
904 Figure 1. Genetic organization and general architecture of the T6SS. (A) Schematic representation of the T6SS core genes. Genes are specified by a letter corresponding to the Tss nomenclature ("A" corresponding to "TssA") or by their vernacular, usual names (Hcp, VgrG, PAAR and ClpV). The color code is shared with panels B and C. (B) Architecture of the T6SS. The membrane complex, composed of the TssJ lipoprotein (orange) and the TssM (blue) and TssL (red) inner membrane proteins, is indicated (OM, outer membrane; PG, cell wall; IM, inner membrane). The different regions of the tail (spike, tube, sheath \& baseplate) are shown. (C) Architecture of a contractile tailed bacteriophage. Components that are shared with the T6SS (spike, tube, sheath \& baseplate) are depicted with the same color code (LTF, long tail fibers).

Figure 2. Interbacterial competition between $E$. coli cells. Time-lapse fluorescence microscopy recordings of GFP-labeled EAEC T6SS ${ }^{+}$cells (green) in presence of mCherry-labeled T6SS ${ }^{-}$prey bacterial cells (red) in T6SS-3 inducing conditions (one image every $7.5 \mathrm{~min}$ ). Prey cells that are killed and not present in the next frame are indicated by white arrows. Scale bar is $5 \mu \mathrm{m}$.

917 Figure 3. Mechanism of action of the T6SS. The biogenesis of the T6SS starts with the assembly of 918 the TssJLM membrane complex (MC) and recruitment of the baseplate complex (BC) (a), which serves as platform for polymerization of the tail tube/sheath structure $(b, c)$. During elongation of the tail structure, effectors (red balls) can be loaded inside the inner tube lumen or attached to the VgrG spike. Following contact with a prey cell, the sheath contracts and propels the inner tube/spike towards the target, allowing penetration and delivery of the effectors (d). Once contracted, the ClpV AAA+ ATPase is recruited to the apparatus for recycling sheath subunits (e, f). The MC (and BC ?) might be re-used for a new round of assembly.

Figure 4. Phylogenetic tree of selected T6SS gene clusters. T6SS gene clusters catagorize in 5 phylogenetic groups (A-E) $(1,2)$. The distribution of the E. coli-associated T6SSs (T6SS-1-3, red) and Salmonella-associated SPI T6SSs (green) is shown, as well as that of E. cloacae and C.rodentium (blue) and the model T6SSs from P. aeruginosa, V. cholerae and F. tularensis (black).

Figure 5. Organization of T6SS-1-3 gene clusters. Genes encoding the T6SS-1 (A), T6SS-2 (B) and T6SS-3 (C) in the indicated E. coli strains are shown schematically. Homologous genes are colored similarly (see box below). When predictable, putative phospholipase effector/immunity pairs (Tle1/Tli1, Tle3/Tli3 or Tle4/Tli4) or $r h s$ genes are indicated. ORFs with unknown function are shown in white. Genes into brackets are not present or not identical in all the strains listed. Genes were identified using the SecReT6 database (114).

Figure 6. Organization of T6SS gene clusters in Salmonella, Enterobacter and Citrobacter. Genes encoding the T6SS in the indicated strains are shown schematically. Homologous genes are colored similarly (see box in Fig. 5). When predictable, rhs genes are indicated. The rhs ${ }^{\text {main }}$ and $r h s^{\text {orphan }}$ ORF shown to undergoes re-arrangements (93) are indicated in the S. enterica Typhimurium SPI-6 gene cluster, as well as the Tae4/Tai4 effector/immunity pairs in S. enterica Typhimurium SPI-6 and $E$. cloacae. ORFs with unknown function are shown in white. Genes were identified using the SecReT6 database (114). Note that the transcription of the C. rodentium tss $M$ gene, interrupted by an early stop codon, is rescued by frameshifting (113).

943 Figure 7. Architecture and structure of the T6SS membrane complex. (A) The tssJ, tssL and tss $M$ 944 genes which encode the components of the membrane complex. (B) Schematic representation of the 945 TssJ, -L and $-\mathrm{M}$ proteins : TssJ is an outer membrane (OM)-tethered lipoprotein whereas TssL and TssM are inner membrane (IM)-embebded proteins. In T6SS-1, the membrane complex comprises an additional protein, TagL, which binds to the peptidoglycan (PG) layer (not depicted here) (27). (C) Crystal structure of the complex between the soluble fragment of TssJ (orange) and the two C-terminal domains of the TssM periplasmic segment (light and dark blue) including the C-terminal helix that 
inserts into the outer membrane (in purple) from EAEC T6SS-1 (PDB: 4Y7O) (Reprinted from reference 26 with permissions). (D) Crystal structure of the cytoplasmic domain of TssL from EAEC T6SS-1 (PDB: 3U66) (33). (E) Negative stain electron microcopy structure reconstruction of the EAEC TssJLM complex (lower panel, EMDB: 2927) (adapted from reference 26 with permissions) (scale bar is $50 \mathrm{~nm}$ ). The position of the outer (OM) and inner (IM) membranes are predicted based on the presence of detergent micelle and the putative location of the trans-membrane segments of TssM, respectively. In the upper panel is shown a top view of the TssJLM complex in which crystal structures of the TssJ-M complex (panel C) are docked, highlighting the presence of two concentric layers closing the channel at the outer membrane.

959 Figure 8. Architecture and structure of the T6SS tail complex. (A) The tssA, tssB, tssC, tssE, tssF, $960 t s s G, t s s, h c p, v g r G$ and paar genes which encode the components of the tail complex (blue, sheath subunits; black, inner tube subunit; green, spike subunits; pink, putative baseplate subunits). (B) Schematic representation of the T6SS tail complex (same color code as panel A). (C) Structural model of EAEC T6SS-1 TssE based on the bacteriophage gp25 crystal structure (PDB: 4HRZ). (D) Composite structure made with the crystal structures (from bottom to top) of the UPEC CTF073 VgrG1 protein (PDB : 2P57) (39), the E. coli O157 EDL933 $\beta$-helical prism (PDB: 3WIT) (40) and the E. coli O6 PAAR protein (PDB: 4JIW) (41). (E) Crystal structure of the EAEC T6SS-1 Hcp hexamer (left, top view; right, side view) (PDB: 4HKH) (42). (F) Cryo-electron micrograph of a contracted T6SS sheath from V. cholerae (left panel, scale bar is $100 \mathrm{~nm}$ ) and atomic-resolution cryoelectron structure of the TssB-C complex (PDB: 3J9G) (47) (adapted from reference 47 with permissions).

Figure 9. T6SS sheath contraction coincides with target cell lysis. Time-lapse fluorescence 972 microscopy recordings of EAEC producing fluorescently-labeled sheath subunits (TssB-sfGFP) in presence of mCherry-labeled T6SS ${ }^{-}$E. coli $\mathrm{K}-12$ prey cells (one image every $7.5 \mathrm{~min}$ ). The time-lapse highlights the assembly and the contraction (white arrow) of the T6SS sheath, followed by the lysis of the target cell. Scale bar is $1 \mu \mathrm{m}$. Adapted from reference 22 with permissions.

976 Figure 10. Regulation of the EAEC T6SS-1 gene cluster. (A) Schematic representation of the promoter organization of the EAEC T6SS-1 gene cluster. The location of the -10 and -35 transcriptional elements (blue), of the Fur-binding sequences (red) and of one of the GATC site (green) are shown. (B) Regulatory mechanism of the EAEC T6SS-1 gene cluster (23). In iron-replete conditions, a Fur dimer (red balls) represses the expression of the T6SS-1 gene cluster by binding to the Fur $^{-10}$ box, which overlaps with the -10 element (OFF). When iron is limiting, the -10 element is available for the RNA polymerase allowing expression of the T6SS-1 genes (ON). Upon replication, the GATC site is methylated $\left(\mathrm{CH}_{3}\right)$ and by preventing Fur binding allows Fur-independent, constitutive expression of the T6SS-1 gene cluster. 


\begin{tabular}{|c|c|c|c|c|c|}
\hline T6SS & $\begin{array}{l}\text { pathotype/ } \\
\text { serotype }\end{array}$ & strain & activity & effector & references \\
\hline \multirow{4}{*}{ T6SS-1 } & \multirow{2}{*}{ EAEC } & \multirow[t]{2}{*}{$17-2$} & biofilm & - & 28 \\
\hline & & & anti-bacterial & $\begin{array}{c}\text { Tle1 } \\
\text { (putative) }\end{array}$ & - \\
\hline & \multirow[t]{2}{*}{ APEC } & \multirow[t]{2}{*}{ TW-XM } & biofilm & - & 77 \\
\hline & & & anti-bacterial & Tle4 & 77 \\
\hline \multirow[t]{4}{*}{ T6SS-2 } & \multirow[t]{3}{*}{ APEC } & DE719 & $\begin{array}{l}\text { attenuated virulence in } \\
\text { ducks, } \\
\text { reduced intracellular in } \\
\text { chicken macrophages }\end{array}$ & - & 12 \\
\hline & & SEPT362 & $\begin{array}{l}\text { attenuated virulence in } \\
\text { chicks }\end{array}$ & - & 80 \\
\hline & & TW-XM & $\begin{array}{l}\text { penetration of the blood- } \\
\text { brain barrier during } \\
\text { cerebral infection }\end{array}$ & - & 77 \\
\hline & MNEC & K1 & $\begin{array}{l}\text { invasion of human brain } \\
\text { microvascular endothelial } \\
\text { cells }\end{array}$ & - & 83 \\
\hline T6SS-3 & EAEC & $17-2$ & anti-bacterial & - & 22 \\
\hline \multirow[t]{5}{*}{ SPI-6 } & \multirow[t]{3}{*}{$S$. Typhimurium } & \multirow[t]{3}{*}{ LT2 } & $\begin{array}{l}\text { affect replication in } \\
\text { macrophage and systemic } \\
\text { dissemination in mice and } \\
\text { in chicks }\end{array}$ & - & $\begin{array}{l}17,79,85 \\
86,89\end{array}$ \\
\hline & & & anti-bacterial & Tae4 & 19,92 \\
\hline & & & anti-bacterial & Rhs ${ }^{\text {orphan }}$ & 93 \\
\hline & $S$. Typhi & Ty2 & systemic infection in mice & - & 84 \\
\hline & E.cloacae & ATCC13047 & anti-bacterial (putative) & Tae4 & 18,73 \\
\hline SPI-19 & S. Gallinarum & $287 / 91$ & $\begin{array}{l}\text { colonization of the gastro- } \\
\text { intestinal tract and } \\
\text { systemic dissemination in } \\
\text { chicks }\end{array}$ & - & 88 \\
\hline CTS1 & C. rodentium & IC68 & anti-bacterial & - & 78 \\
\hline
\end{tabular}

Table 1. Phenotypes and effectors associated with T6SS in E. coli, Salmonella and related species. 


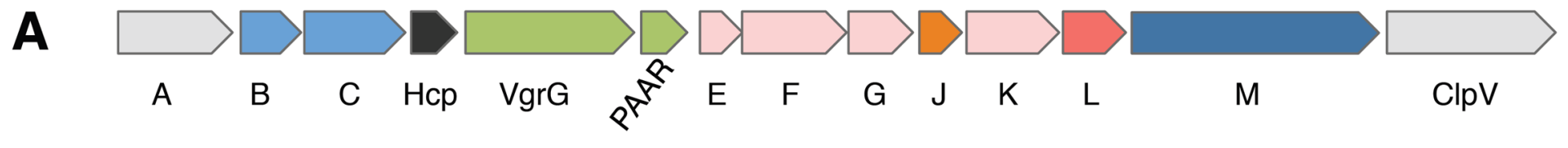

B
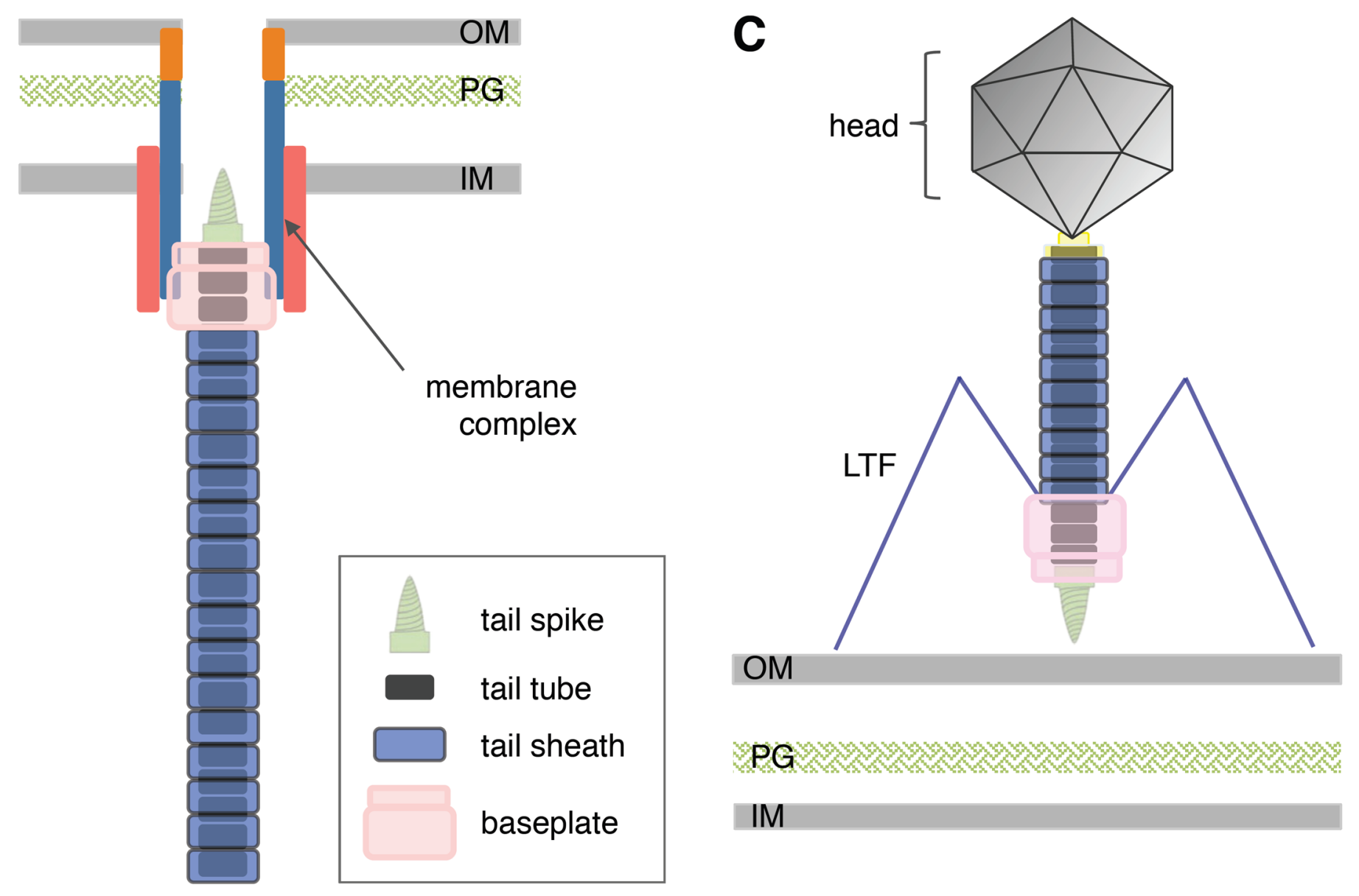

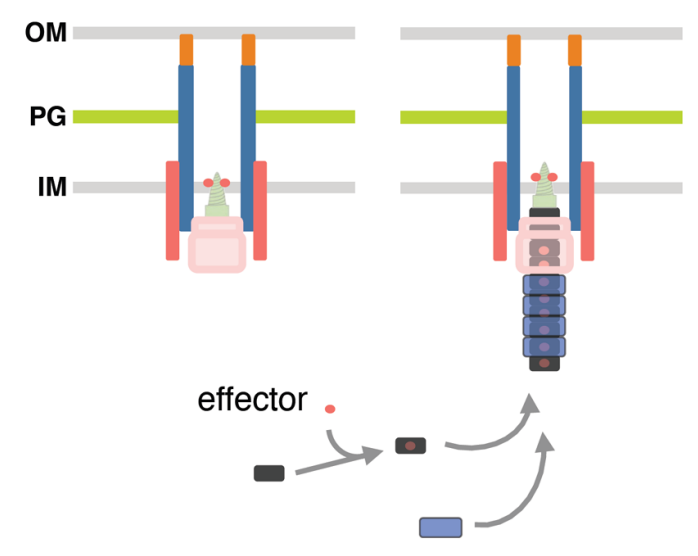

a

b

assembly
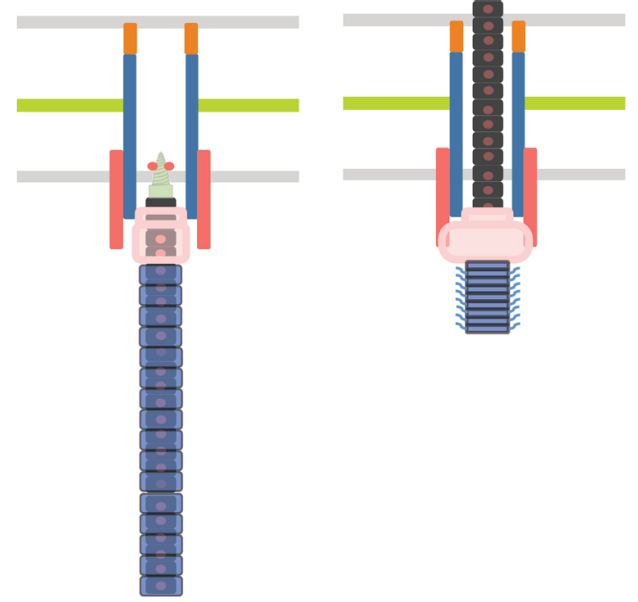

\begin{abstract}
C
\end{abstract}
d

contraction

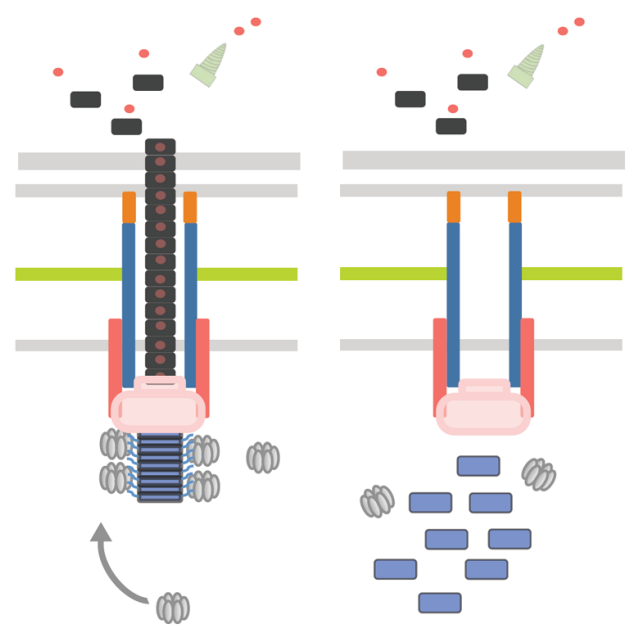

ClpV

ATPase

e

\begin{tabular}{ll}
$e$ & $f$ \\
\hline recycling
\end{tabular}

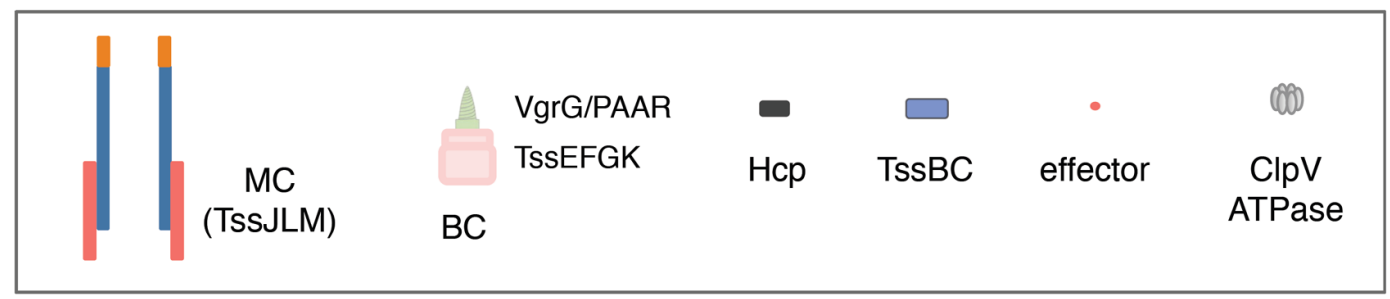




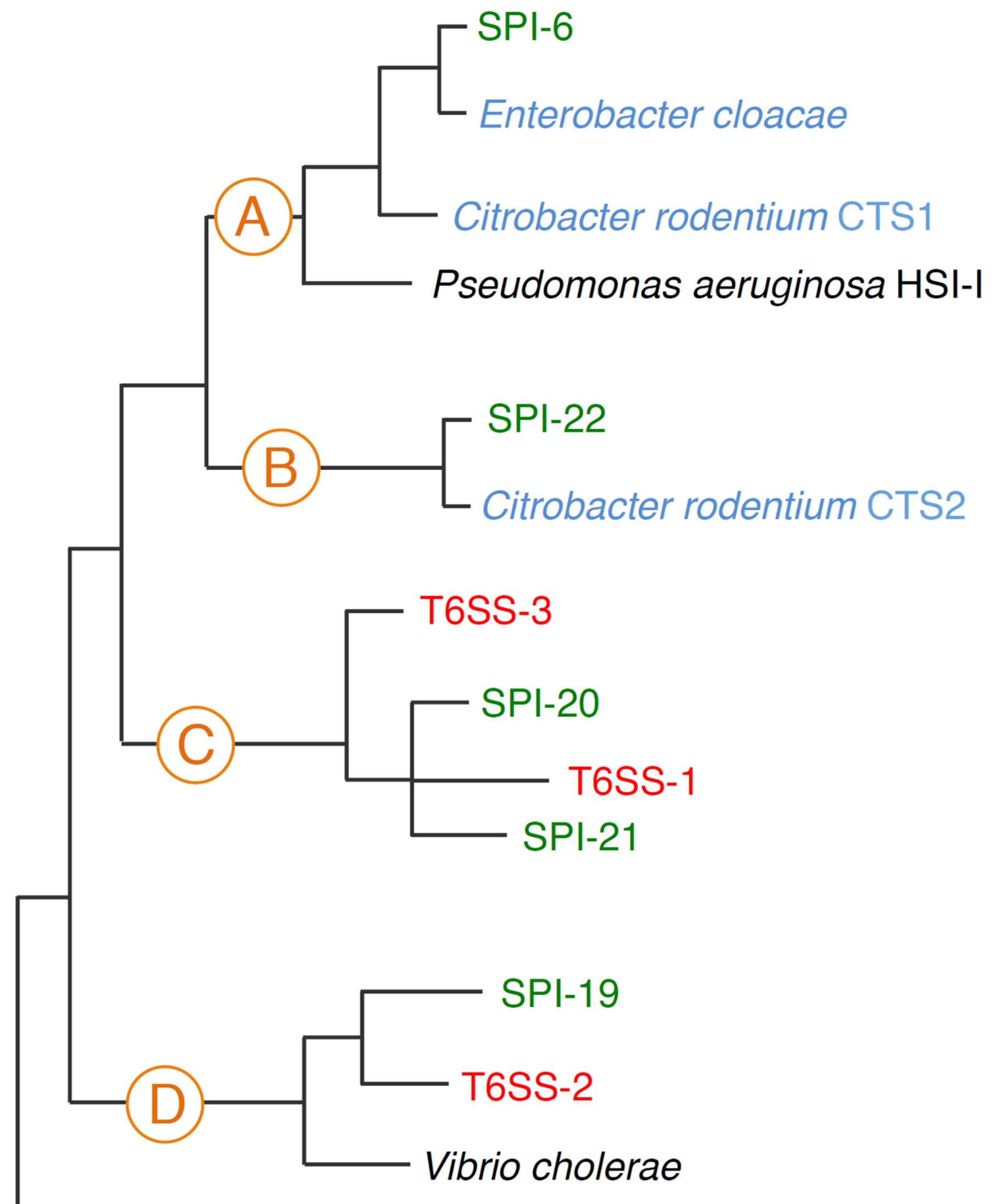




\section{A T6SS-1}

EAEC 042

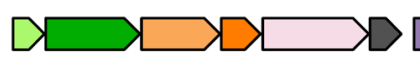

Tle1 Tli1

AIEC LF82 / UPEC CFT073
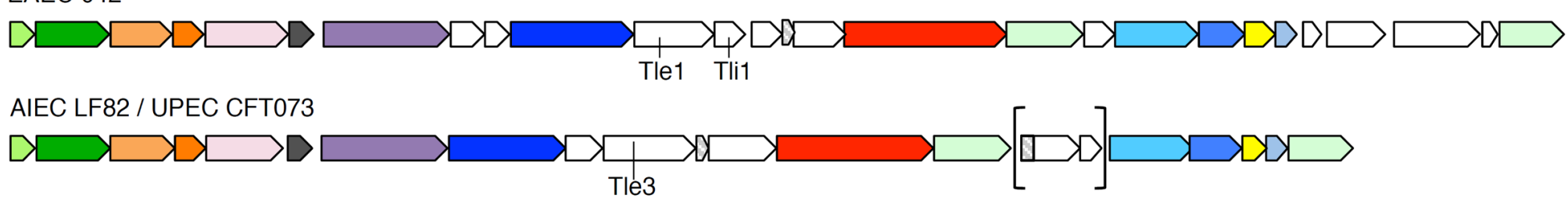

UPEC UTI89/APEC TW-XM/APEC ED205

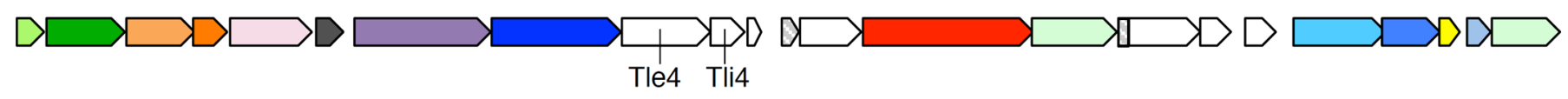

\section{B T6SS-2}

E. coli W / EHEC EDL933 / ETEC E24377A / S. sonnei Ss046 /S. enterica Gallinarum SPI-19
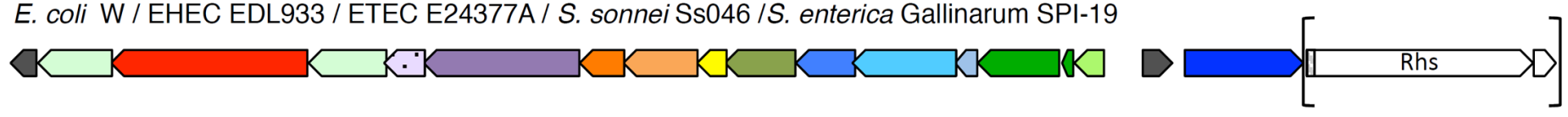

EAEC 042 / AIEC LF82 / UPEC UT189 / UPEC 536 / MNEC K1 RS218 / APEC TW-XM
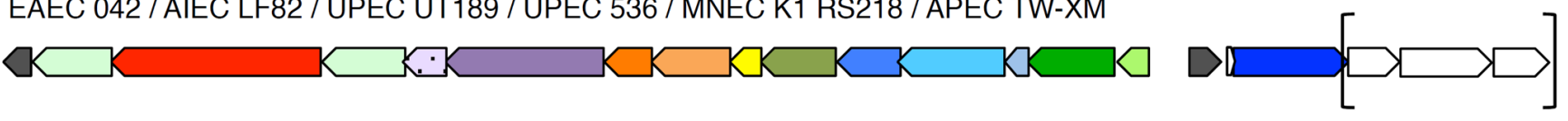

\section{T6SS-3}

EAEC 042 / APEC ED205 / STEC/EAEC 0104:H4

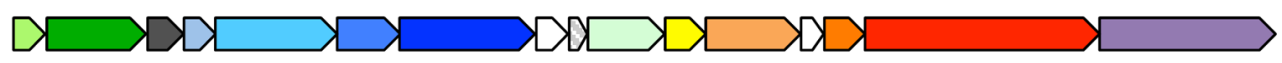

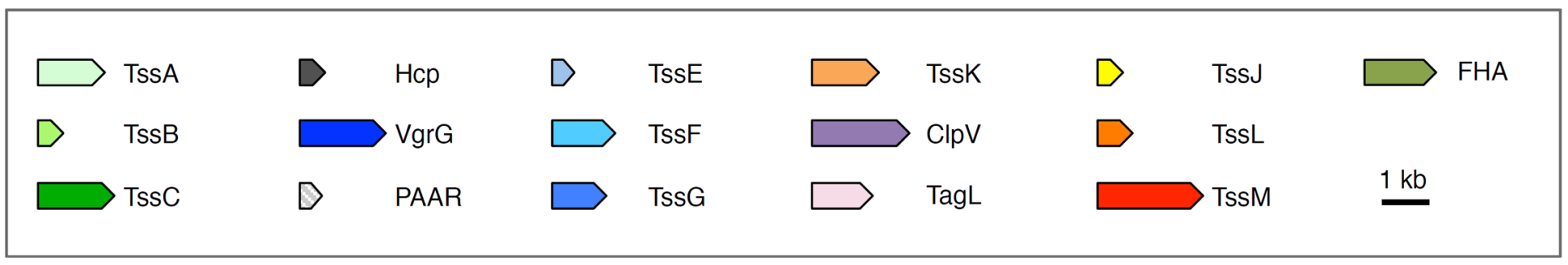




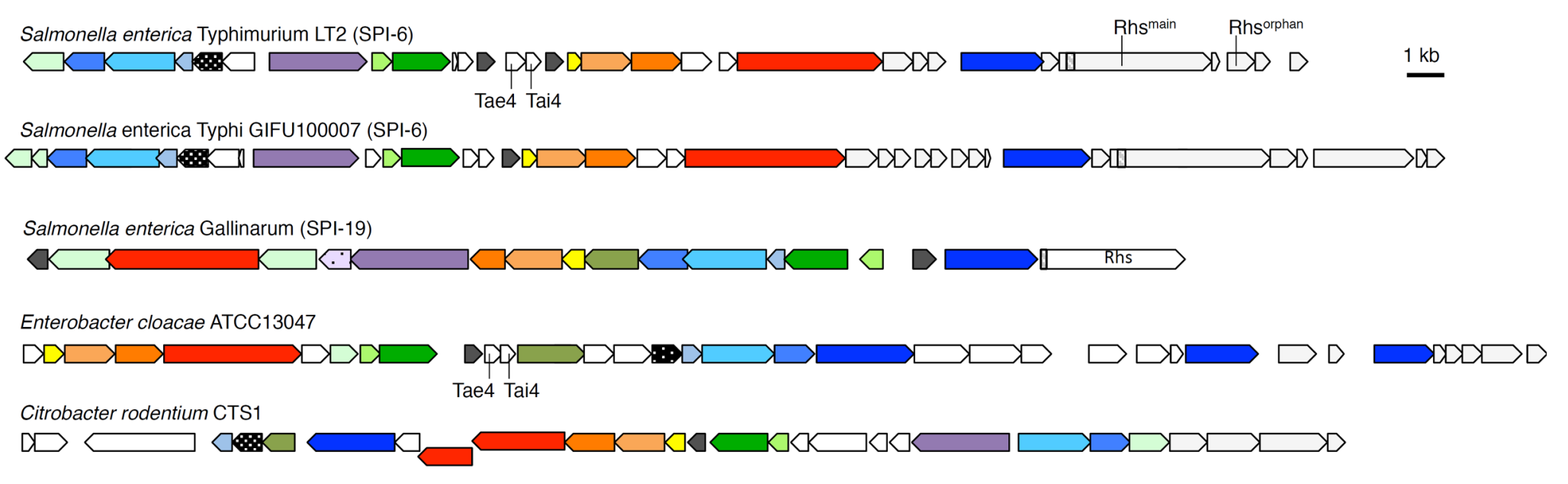



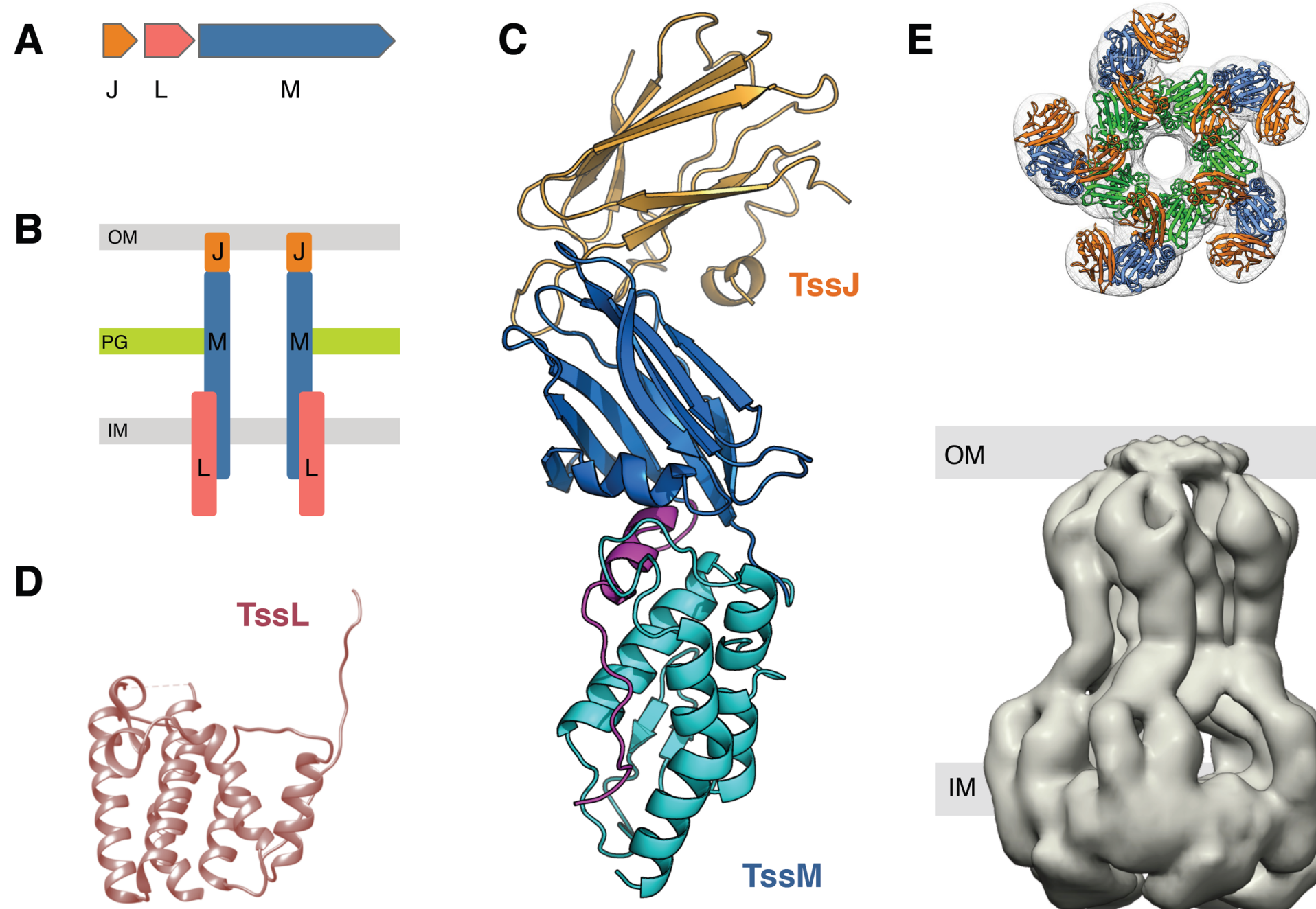

D
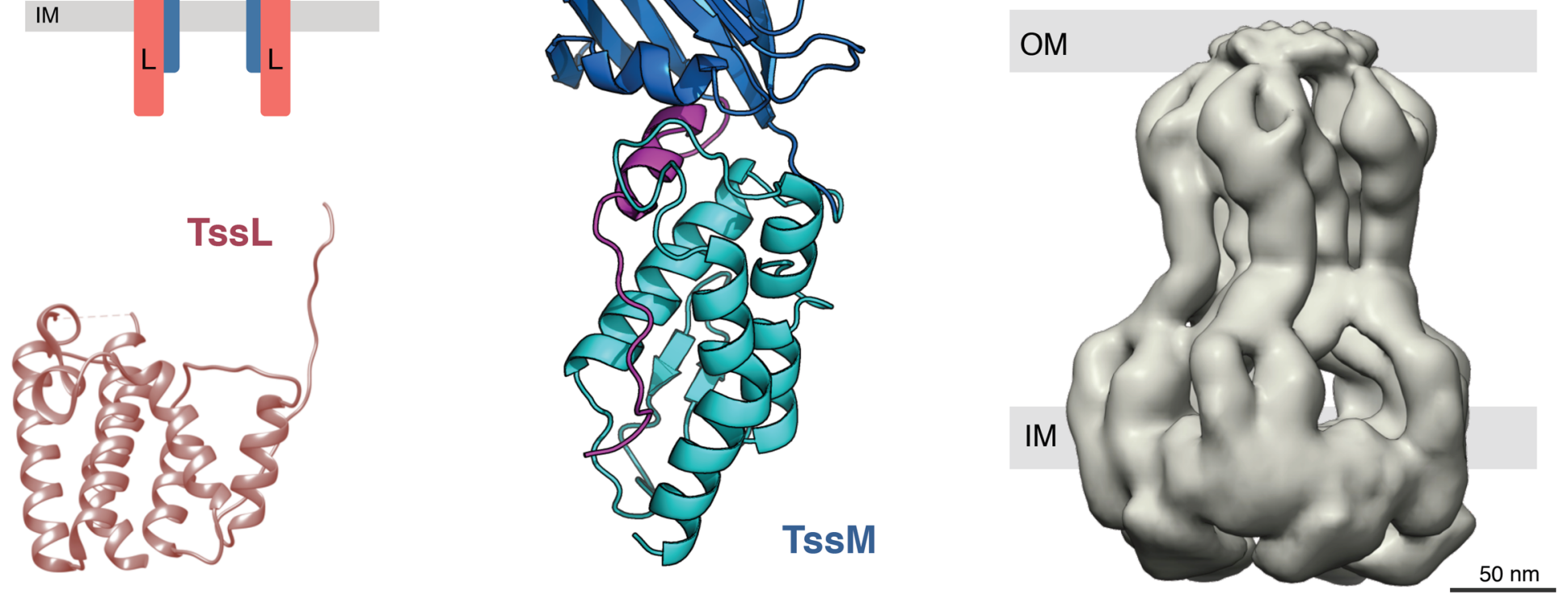
A

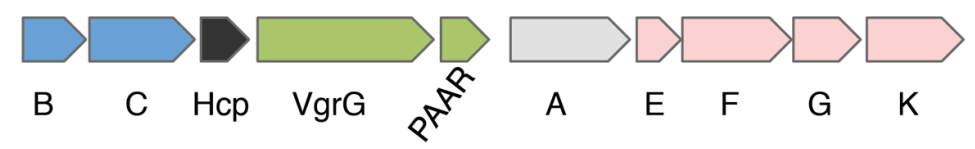

B

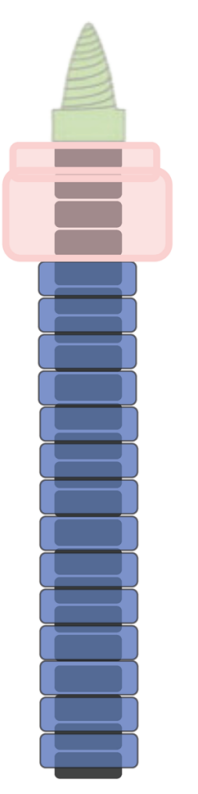

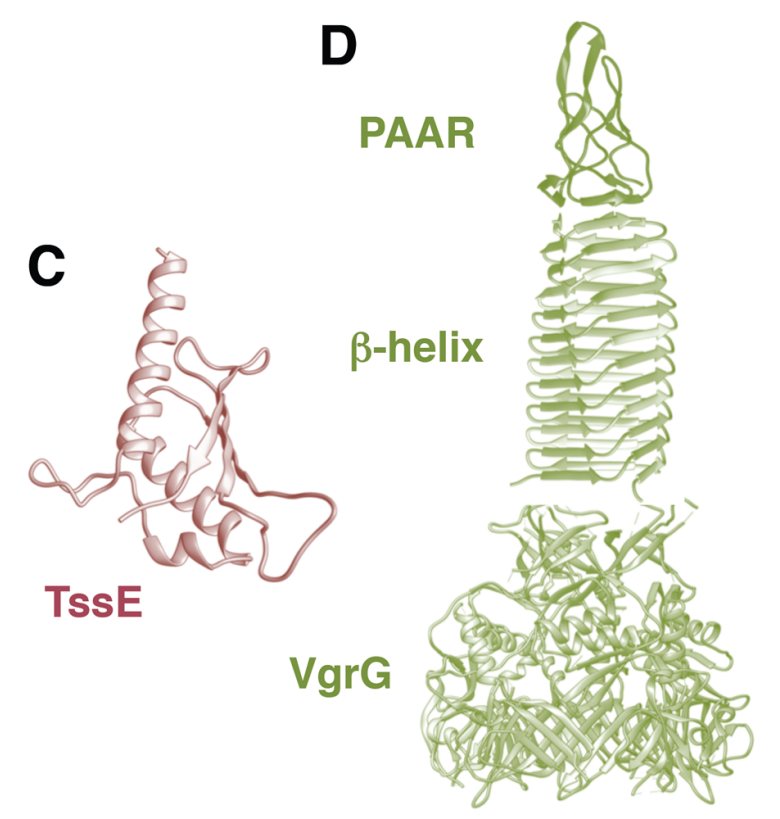
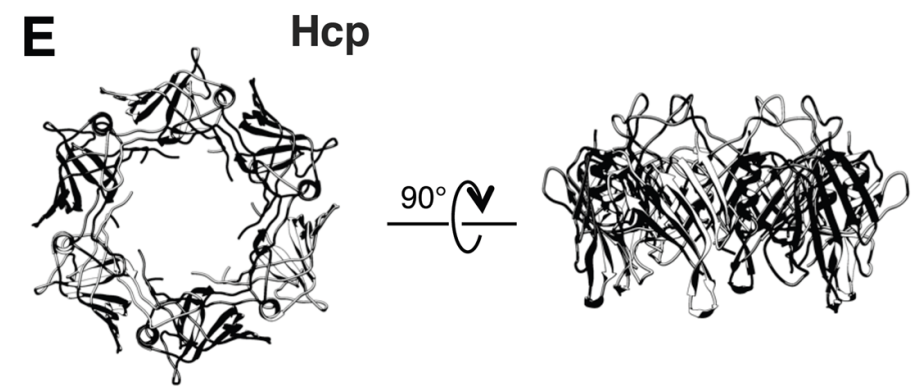

F

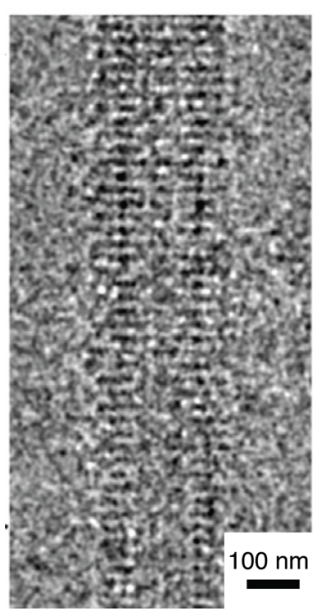

TssBC

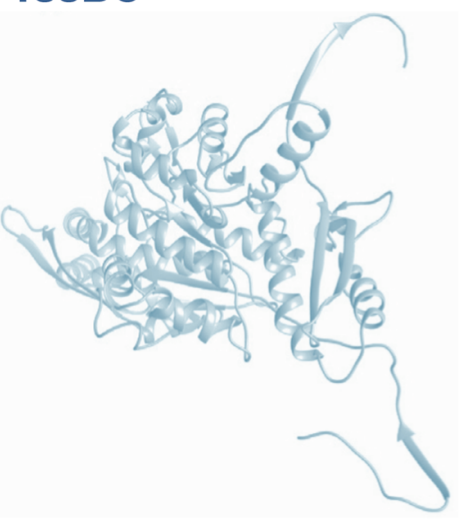




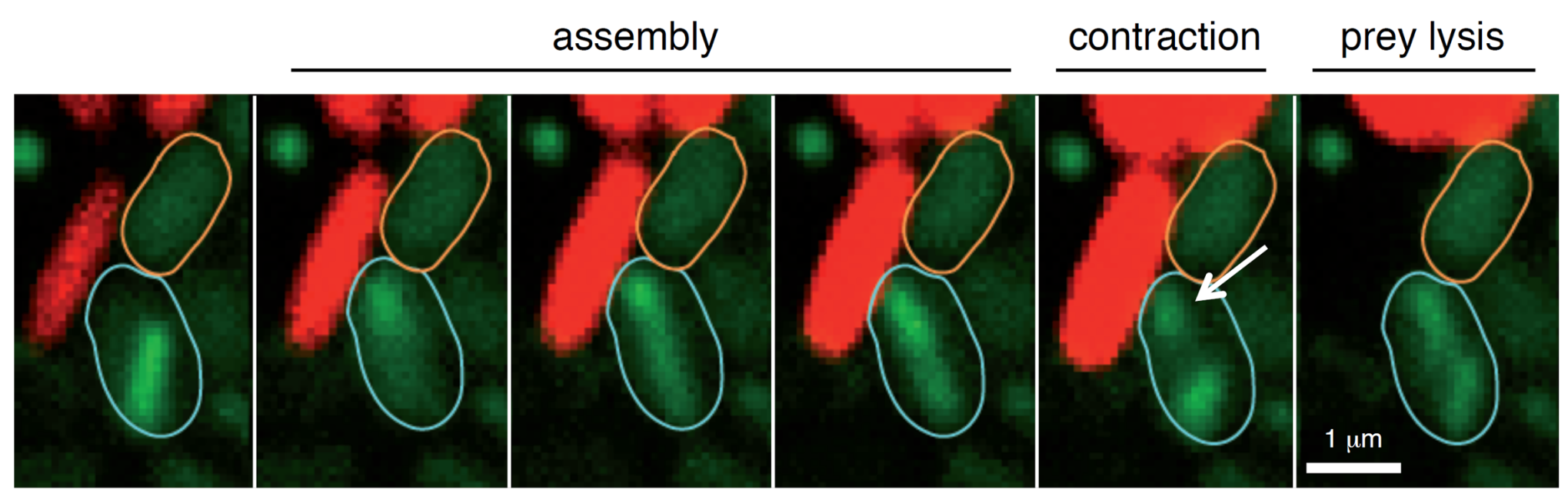




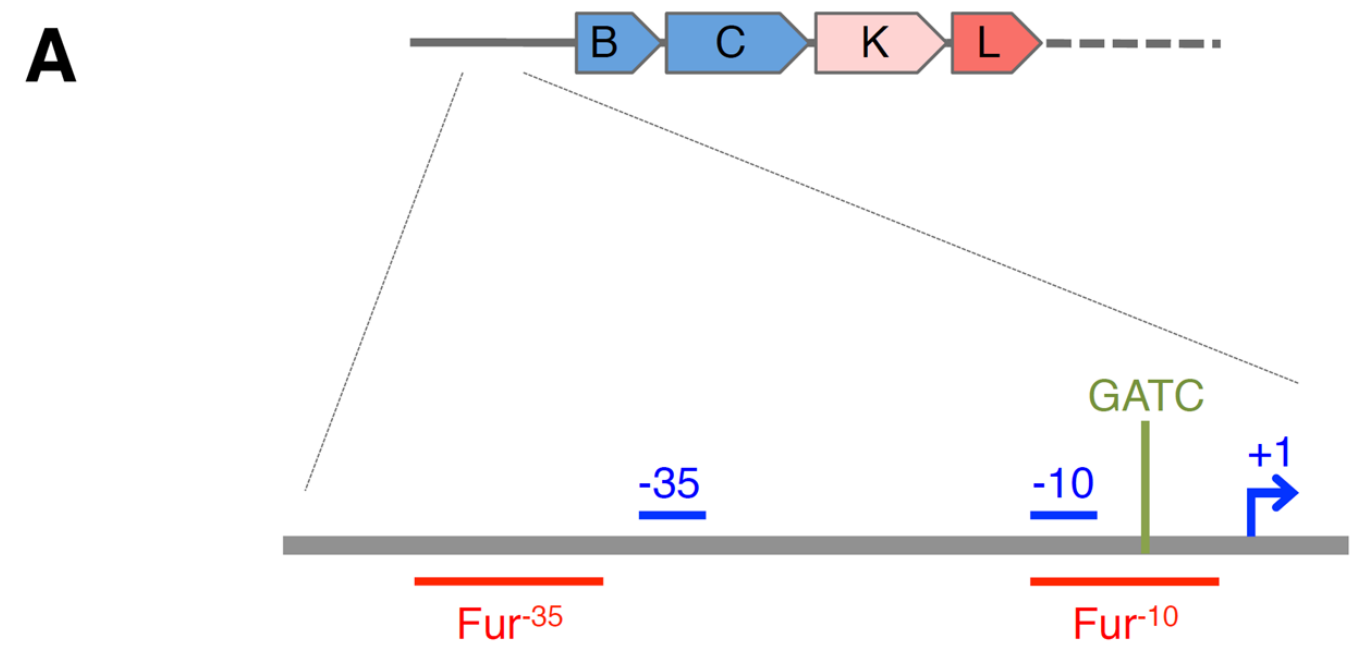

B

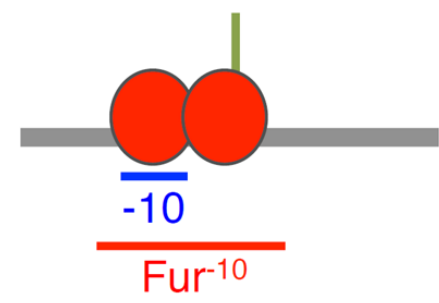

OFF

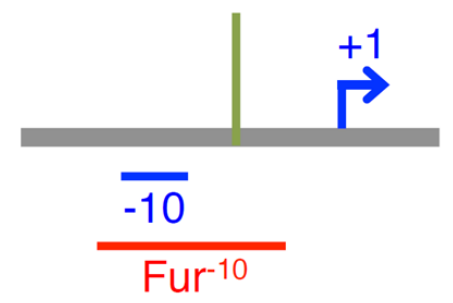

ON

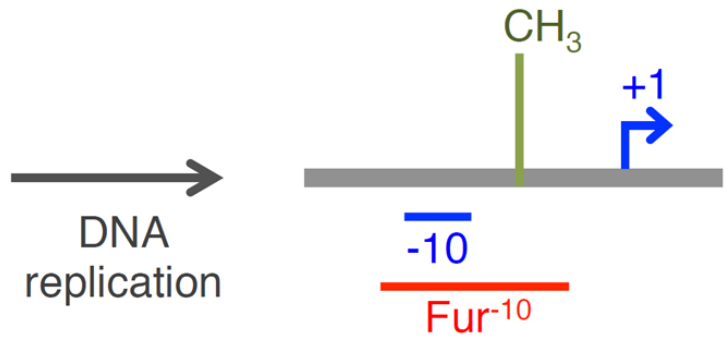

constitutive ON 